\title{
Incomplete recovery to enhance economic growth losses from US hurricanes under global warming
}

Christian 0tto ( $\nabla$ christian.otto@pik-potsdam.de)

Potsdam Institute for Climate Impact Research https://orcid.org/0000-0001-5500-6774

Kilian Kuhla

Potsdam Institute for Climate Impact Research https://orcid.org/0000-0002-8698-1246

\section{Tobias Geiger}

German Metrological Service

Jacob Schewe

Potsdam Institute for Climate Impact Research https://orcid.org/0000-0001-9455-4159

Katja Frieler

Potsdam Institute for Climate Impact Research https://orcid.org/0000-0003-4869-3013

\section{Article}

Keywords: economic growth losses, hurricanes, disaster insurance, global warming, economic recovery

Posted Date: January 20th, 2022

DOI: https://doi.org/10.21203/rs.3.rs-654258/v2

License: (c) (1) This work is licensed under a Creative Commons Attribution 4.0 International License. Read Full License 


\title{
Incomplete recovery to enhance economic growth losses from US hurricanes under global warming
}

\author{
Christian Otto ${ }^{+a,{ }^{*}, \text { Kilian Kuhla }}{ }^{+a, b}$, Tobias Geiger ${ }^{a, c}$, \\ Jacob Schewe ${ }^{a}$, Katja Frieler ${ }^{a}$ \\ apotsdam Institute for Climate Impact Research, Telegrafenberg A56, Potsdam, Germany \\ bInstitute of Physics, Potsdam University, Karl-Liebknecht-Str. 24, Potsdam, Germany \\ ${ }^{c}$ Deutscher Wetterdienst, Klima und Umwelt, Potsdam, Germany \\ ${ }^{\dagger}$ with equal contributions \\ *Correspondence to: christian.otto@pik-potsdam.de
}

\begin{abstract}
Ongoing global warming is likely to increase the return frequency of very intense hurricanes in the North Atlantic. Here, we analyse how this frequency increase may impact on economic growth. To this end, we introduce an event-based macroeconomic growth model that temporally resolves how growth depends on the heterogeneity in timing and intensity of hurricane impacts. We calibrate the model to the United States and find that economic growth losses scale super-linearly with their heterogeneity. We explain this by a disproportional increase of indirect losses with event severity which can lead to an incomplete recovery of the economy between consecutive intense landfall events. Based on two different methods to estimate the future frequency increase of intense hurricanes compared to the period 1980-2014, we estimate annual growth losses to increase between $10 \%$ and $146 \%$ in a Paris-compatible $2^{\circ} \mathrm{C}$ world and even up to $522 \%$ in a $2.7^{\circ} \mathrm{C}$ world in compliance with the median end-of-century warming under currently implemented or enacted policies. We finally study the efficacy of disaster insurance as an adaptation strategy and find that higher insurance coverage may higher insurance coverage may be a viable means to mitigate these climate change-induced increases in growth losses.
\end{abstract}




\section{Introduction}

Already in the present climate, hurricanes in the North Atlantic cause substantial economic losses in the United States (US). Between 1980 and 2019, these storms caused on average losses about US\$ 31 billion in direct economic losses per year, peaking at US\$266.5 billion in 2005 according to MunichRe's NatCatSERVICE database ${ }^{1}$. Moreover, there is increasing empirical evidence that, in addition to these direct losses, tropical cyclones can substantially reduce economic growth of affected countries for more than a decade $2 ; 3 ; 4$. These long-term growth impacts may have important implications for the adaptation to, and coping with, the impacts of tropical cyclones under global warming, since there is strong evidence that the proportion of very intense storms may increase ${ }^{5 ; 6 ; 7}$. There are at least two mechanisms through which this increase could overcompensate a possible mild decline of the overall number of tropical cyclones ${ }^{5}$ driving up economic losses. First, the most intense storms cause dis-proportionally larger direct economic losses than smaller storms. For instance, major hurricanes of the two highest categories 4-5 on the SaffirSimpsons scale ${ }^{8}$ have accounted for almost half of normalised economic damage from all hurricanes that made landfall in the US in the period 1900-2005 despite representing only about $6 \%$ of landfall events ${ }^{9}$. Second, an increase of the return frequency implies that, on average, there is less time for the economy to recover in between consecutive events; incomplete recovery has been identified as one main factor that may increase the vulnerabilities of the economy to climate extremes and thereby drive up losses ${ }^{10 ; 11}$.

Catastrophe insurance is discussed as a means to reduce vulnerabilities of the economy to extreme weather events by shortening the recovery time in the disaster aftermath ${ }^{12 ; 13 ; 14 ; 15}$, and it may thereby even promote economic growth on the macroeconomic level ${ }^{16}$. These promising findings may explain the rising popularity of multilateral climate risk insurance schemes and the G20 InsuResilience Global Partnership initiative ${ }^{17}$. However, it remains an open question whether higher insurance coverage and better insurance schemes will be sufficient to counteract climate change impacts in a warming world ${ }^{18 ; 19}$.

Progress in answering this question has been also made difficult by the limitations of state-of-the-art climate integrated assessment models (IAMs). These standard workhorses for climate policy assessments (see $20 ; 21$ for detailed reviews of IAMs)) - such as the seminal DICE model ${ }^{22}$ which is used by the US government to estimate the cost of carbon 
emissions to society - have been criticised for not being able to appropriately account for the impacts of climate extremes ${ }^{23 ; 24}$. The main reason is that the coarse temporal resolution of most models (typically 1-10 years) simply does not allow for the representation of individual extreme weather events; potentially important non-linearities arising from a disproportional increase of total economic losses with impact intensity or from incomplete recovery between consecutive events cannot be resolved. In consequence, IAM-based studies usually report relatively small, or even negligible, impacts of climate extremes on the economy ${ }^{25 ; 26}$ which are at odds with recent estimates in the climate econometric literature $27 ; 3 ; 2$

\section{Main}

Here, we first study how the heterogeneity of US hurricane impacts has affected economic growth in the period 1980-2014. We then project increases in growth losses that would arise from changes in the return frequencies of the storms and associated changes in storm number and impact heterogeneity in a Paris-compatible $2^{\circ} \mathrm{C}$ world as well as in a world, which is $2.7^{\circ} \mathrm{C}$ warmer than in preindustrial times corresponding to the median warming estimate by 2100 under the currently implemented or enacted policies ("current policy path") ${ }^{28}$. Since there is substantial uncertainty on how the return frequencies of hurricanes will change with global warming, and the magnitude of the effect strongly depends on the underlying methodology used to estimate this change ${ }^{5}$, we consider two different approaches at both ends of the uncertainty range. In addition, we assess the efficacy and limits of disaster insurance in mitigating the climate change-induced increase in growth losses. To this end, we build a simple - and transparent - event-based neoclassical growth model for a national economy. The model accounts for losses to the stock of physical assets that result from individual landfall events. Reconstruction investments can be capped in the disaster aftermath to describe inefficiencies slowing down the economic recovery such as scarcity of trained labour and building materials and other financial and technical constraints in the reconstruction process ${ }^{29 ; 30}$. Further, we integrate a compulsory non-profit hurricane insurance financed by a flat fee on all citizens, regardless of their individual risk ${ }^{12}$. This insurance scheme represents a precautionary 
savings mechanism where premiums accumulated in normal times are issued to affected households in the disaster aftermath.

In the standard calibration of the model, the insurance ratio is set to $50 \%$ the average ratio of insured losses in the US between 1980 and 2014 according to the NatcatSERVICE database ${ }^{1}$ and reconstruction investments are capped to $0.2 \%$ of weekly output following ref. ${ }^{29}$. This model calibration allows us to obtain average annual output growth losses that are comparable to those reported in the recent climate econometric literature ${ }^{2 ; 4}$ when driving the model with the direct asset losses of the 88 hurricanes that made landfall in the US in the period 1980-2014 according to the NatCatSERVICE database ${ }^{1}$.

\section{Insurance accelerates economic recovery}

To illustrate the interplay of insurance payouts and limits of reconstruction investments, we first study the economic recovery dynamics in the aftermath of an individual storm that destroys $1 \%$ of the physical capital stock in month 3 (Fig. 1A). Besides the "realistic" standard calibration of the model (or scenario) (green full lines), we consider two limiting scenarios, one without insurance (red lines) and one with full insurance coverage of all losses (blue lines). Further, to test the sensitivity of the model with regard to the construction investment cap, we consider a 1\% reconstruction investment cap (dashed lines) in addition to the $0.2 \%$ reconstruction investment cap (solid lines) and contrast both to a limiting case where all available investments (difference between output and savings) can be used for reconstruction ("no investment cap", dotted lines) (Fig. 1B). Since insurance premiums depend on insurance coverage, each growth trajectory is normalised to the balanced growth path of an unperturbed economy with the same insurance premium. To account for delays in insurance payouts, we fit data on cumulative insurance payouts of the Reinsurance Association of America ${ }^{31}$ indicating that $60 \%$ (90\%) of the insured losses are paid out after one (three) year(s) with a sigmoidal function (see Methods for details). The resulting weekly payouts are shown in the inset of Fig. 1B.

Generally, the recovery of the economy can be divided into a first phase of rapid reconstruction of destroyed capital, and a second phase, where the economy slowly approaches the balanced growth path of the unperturbed system. The recovery speed in the first phase is reduced when the reconstruction investment cap is lowered. For the 


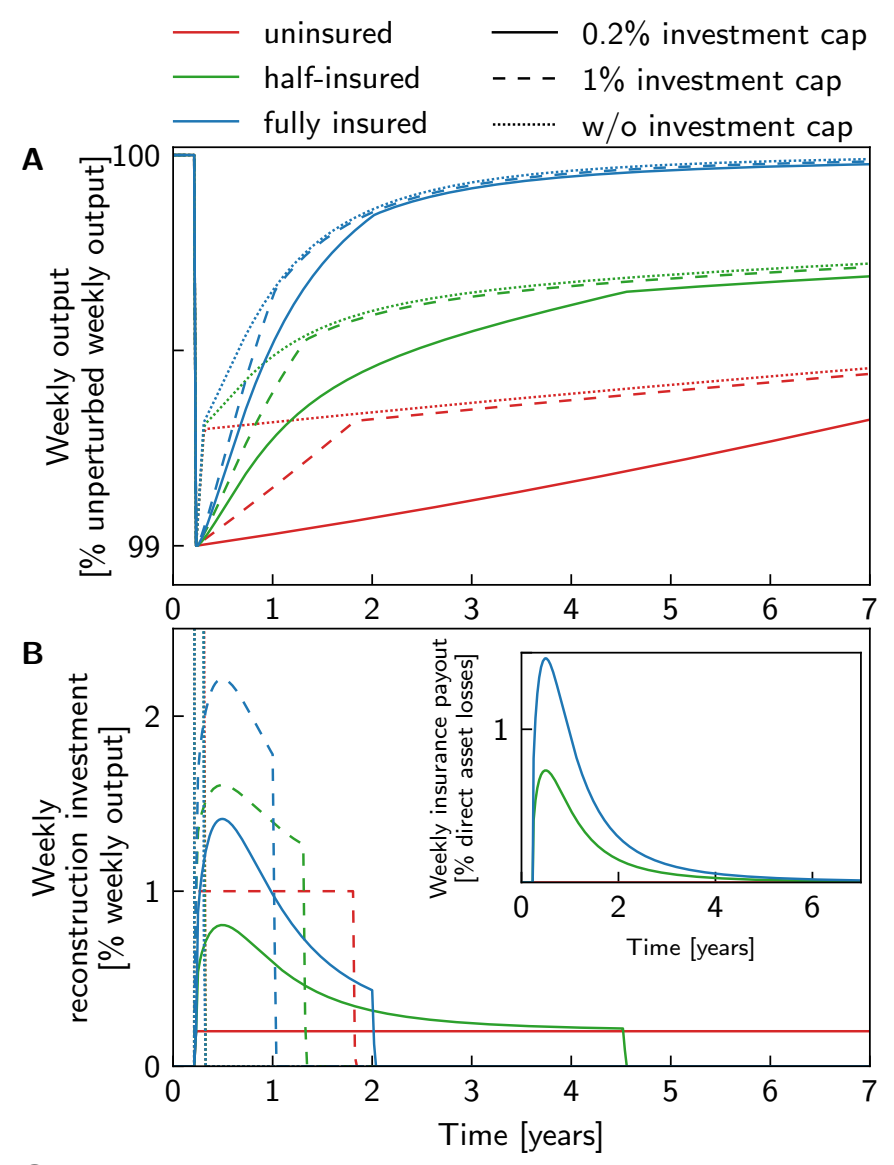

C

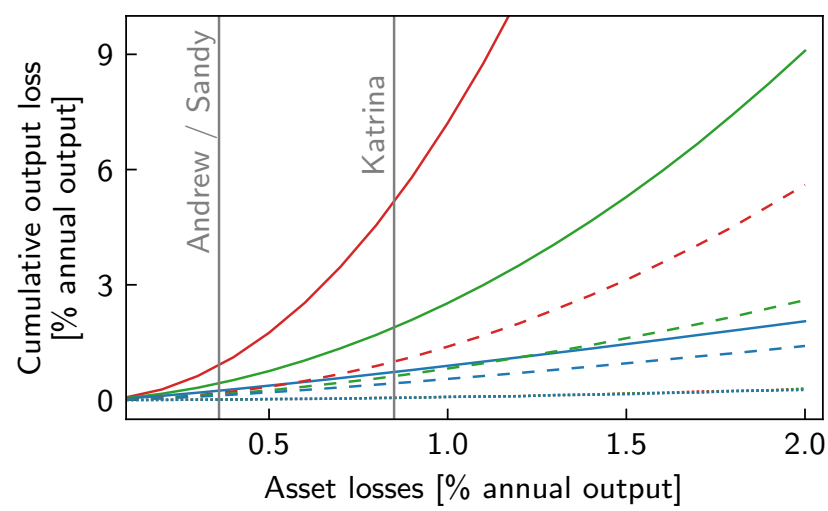

Fig. 1. The contribution of insurance and reconstruction investment on the economic recovery dynamics in the aftermath of an individual hurricane with landfall. Response dynamics in the aftermath of a $1 \%$ shock to the capital stock with no (red), $50 \%$ (green), and full (blue) insurance coverage, for scenarios where maximum weekly reconstruction investment is not limited (dotted lines) as well as limited to $0.2 \%$ (solid lines) and $1 \%$ (dashed lines) of weekly output, respectively. A Time series of weekly output relative to the output of an unperturbed economy on the balanced growth path. B Time series of weekly reconstruction investment (in \% of weekly output) and weekly insurance payout (in \% of direct asset losses to the capital stock, inset). C Cumulative output losses until full recovery of production capacity as a function of the direct asset losses (both in terms of annual output in the year before the landfall). Vertical grey lines indicate the asset losses caused by the historical major hurricanes Sandy, Andrew, and Katrina according to the NatCatSERVICE database ${ }^{1}$. 
scenario with the lowest reconstruction investment cap and no insurance, the cap even limits the recovery dynamics in the slow second phase (red solid lines in Fig. 1A). In line with empirical findings, recovery speed increases with insurance coverage for two reasons ${ }^{32 ; 33}$ : First, since insurance provides additional financial means for reconstruction, the reconstruction investment cap can be temporarily exceeded, e.g., to compensate for scarcity driven wage increases ${ }^{34}$. This accelerates the recovery process especially in the first reconstruction phase. Second, the larger the insurance coverage the lower is the share of the output that has to be reinvested in reconstruction efforts. In consequence, more output can instead be invested in new capital. This fosters output growth especially in the slow recovery phase. Except in the limiting, overly optimistic, case of full insurance coverage and no reconstruction investment cap, cumulative output losses increase superlinearly with the size of the direct asset losses, i.e. indirect losses increase faster than shock size (Fig. 1C). In consequence, in the aftermath of intense hurricane shocks it can take multiple months or even years for the economy to recover. For instance, in the standard scenario, it takes more than 5 months for the production capacity to recover after the major hurricanes Andrew and Sandy that struck Florida and Louisiana in 1992 and New York and New Jersey in 2012, respectively, both causing asset losses equivalent to about $0.4 \%$ of the US's annual output in the years of landfall, respectively (grey vertical lines in Fig. 1C). Further, our modelling suggests that in the aftermath of the largest historical loss event, the landfall of hurricane Katrina in New Orleans in 2005, that caused asset losses equivalent to $0.8 \%$ of the US's annual output in this year, it took more than one year and a half for the production capacity to recover.

\section{Growth losses increase with shock heterogeneity}

Next, we study how the economic response dynamics depends upon the heterogeneity of hurricane shocks (Fig. 2). For that, we assume that landfall events are Poisson ${ }^{35}$ distributed within the US hurricane season (June-November). Further, we assume that direct asset losses (relative to the gross domestic product (GDP) in the year of landfall) are log-normally distributed (see supplementary Fig. S5 for a log-normal fit of the data). This yields conservative damage estimates as even power law distributions with higher tail risk are currently discussed for US hurricane damages ${ }^{36 ; 37}$. In the remainder of this paper, 


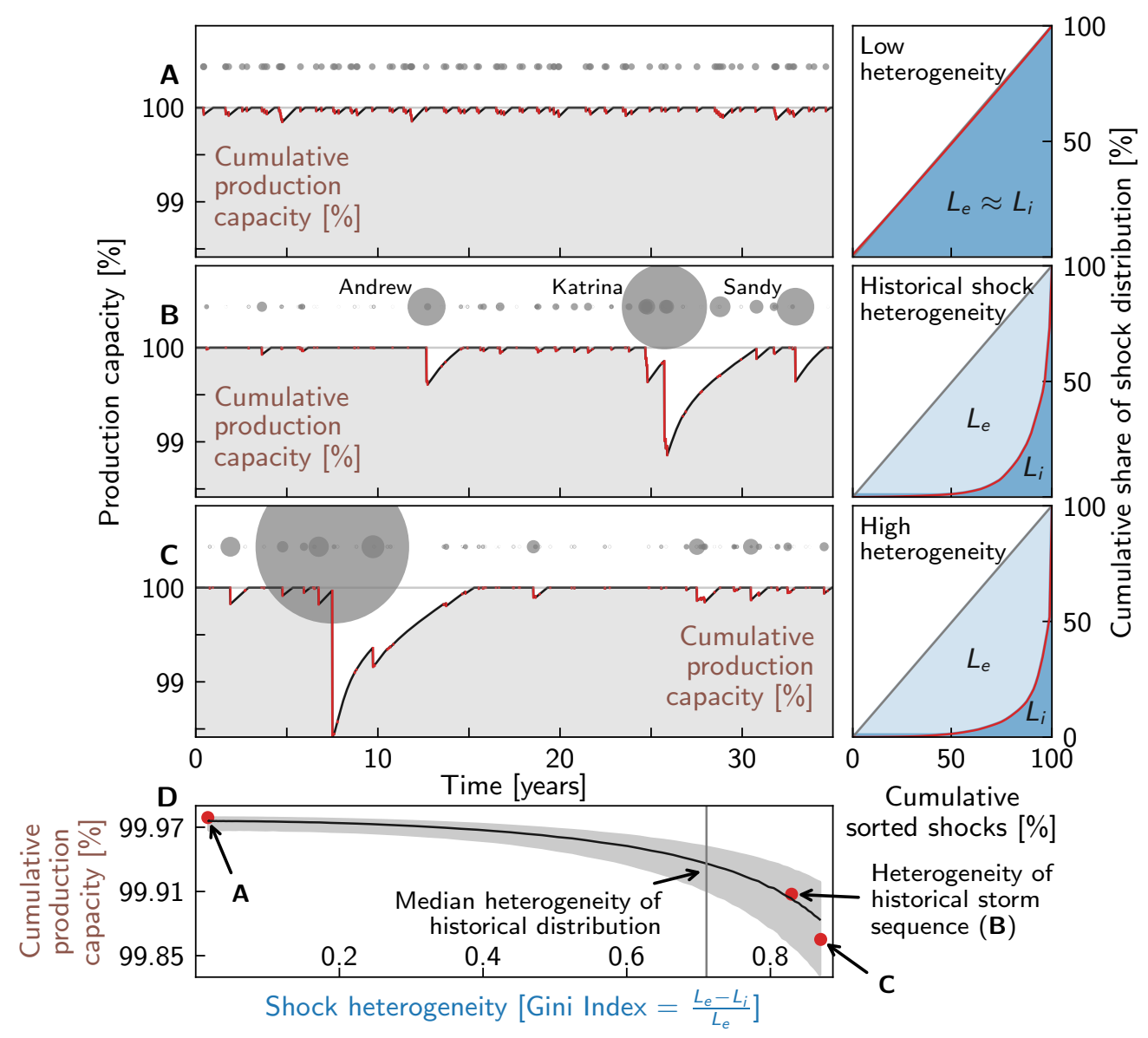

Fig. 2. Recovery dynamics of production capacity in dependence of hurricane shock heterogeneity. Economic impacts of hurricane shocks for a period of 35 years. The heterogeneity of shocks increases from $\mathbf{A}$ to $\mathbf{C}$. Hurricane number and relative cumulative asset losses are fixed to the 88 hurricanes that reportedly made landfall in the United States in the period 1980-2014 and caused $3.24 \%$ of cumulative asset losses (relative to the growth domestic product of the years the hurricanes made landfall) according to the NatCatSERVICE database ${ }^{1}$. B depicts the impacts of the observed historical time series of hurricanes with landfall. Left panel: Exemplary time series of available production capacity (in \% of full production capacity (grey horizontal lines)). Periods of reduced capacity in the disaster aftermaths are marked in red and shocks are marked by grey dots with the size of the dots indicating the shock size. Right panel: Lorenz curves to illustrate the heterogeneity of the shock distribution. Red lines indicate the cumulative share of production capacity losses as a function of the cumulative share of the shocks. Grey diagonal lines indicate the Lorenz curves for equally distributed shocks. The Gini index $G \equiv \frac{L_{e}-L_{i}}{L_{e}}$ as measure for shock heterogeneity is determined by the ratio of the areas under the red $\left(L_{e}\right.$, light blue shading) and blue lines $\left(L_{i}\right.$, dark blue shading). D Mean cumulative available production capacity (in $\%$ of the production capacity of unperturbed system) as a function of the Gini index. Red dots and grey shaded areas indicate the values of the Gini index obtained for the runs in A-C and the 16.7-83.3 percentile confidence interval, respectively. The grey vertical line indicates the median Gini index of the historical shock distribution (see Methods). Other parameters: Insurance coverage 50\%; reconstruction investment cap $0.2 \%$ of weekly output. 
we will refer to the distribution of relative asset losses as shock distribution. As detailed in Sec. A.3 of the Methods, drawing from this shock distribution allows us to generate synthetic time series of asset losses with defined length, event number, and value for the cumulative relative asset losses. To isolate the impact of shock heterogeneity, we then vary the heterogeneity of the asset losses - measured by the Gini index $(G)$ of the event distribution - but keep the number of hurricanes with landfall (88) (and thus average hurricane return frequency) as well as relative cumulative direct asset losses (3.24\% of cumulative output) at their values reported in the NatCatSERVICE database ${ }^{1}$ fixed for the study period 1980-2014 (35 years). Here, normalization of direct asset losses relative to real national GDP in the year of impact allows us to generate representative synthetic time series irrespective of the year of occurrence of each underlying event. Note that we thereby adjust losses for inflation and economic growth but assume no changes in vulnerability (e.g., due to adaptive measures taken on the ground), see refs. ${ }^{38 ; 39 ; 40}$ for a discussion on different normalization approaches with respect to hurricane damages.

For a nearly homogeneous shock distribution $(G=0.018)$, asset losses (grey circles in (Fig. 2A-C) are relatively small and production capacity can mostly recover between loss events and stays close to the one of the unperturbed system for the whole study period (Fig. 2A). For higher values of the Gini index, we obtain many small but few high intensity loss events. Since cumulative output losses increase dis-proportionally with event intensity (cf. Fig. 1C), also the risk for incomplete recovery between events increases for higher values of the Gini index (cf. Fig. $2 \mathbf{B}$ and $\mathbf{C}$ for $G=0.83$ and $G=0.87$ ). For instance, when driving the model with the historical sequence of landfall events, we find that the US economy may not have recovered in between the major hurricanes Katrina and Sandy (Fig. 2B).

To gain a systematic understanding on how production capacity depends upon shock heterogeneity, we study the cumulative production capacity over 35 years as a function of shock heterogeneity. For a given shock distribution, cumulative production capacity in general differs between event realisations due to differences in the timing and the size of the shocks. To account for this uncertainty, we generate a large ensembles of 20,000 realisation for each shock distribution. The cumulative production capacity is then plotted as a function of the median Gini index as obtained across all realisations (see Sec. A.2 of Methods) (Fig. 2D). (Note that values of the Gini index for individual realisations may 
substantially deviate from the median Gini index. For instance, the Gini index for the observed historical storm sequence ( $G=0.83$ ) is substantially higher than the median value of the Gini index across all realisations for the historical storm distribution ( $G=0.71)$ (compare red dot to vertical grey line in Fig. 2D).) We find that the available production capacity reduces super-linearly with increasing shock heterogeneity. The reduction is strongest in the high heterogeneity range to the right of the median Gini index for the historical period (grey line in Fig. 2D), where incomplete recovery becomes more likely.

Similarly, economic growth declines super-linearly with increasing shock heterogeneity (Fig. 3). Besides the standard scenario with a $0.2 \%$ reconstruction investment cap and $50 \%$ insurance coverage (red line in Fig. 3B), we again consider scenarios with a $1 \%$ and no investment cap (green and blue lines in Fig. 3) as well as the limiting cases of no and complete insurance (Fig. 3A and Fig. 3C). We find that the dependence of economic growth on shock heterogeneity increases when i) the reconstruction investment cap and ii) the insurance coverage is lowered.

For low values of the investment cap, the growth reduction with increasing shock heterogeneity can be quite substantial. For instance, for the standard scenario, annual growth losses increase by more than $16 \%$ from 0.0238 percentage points (p.p.) for the lowest to 0.0275 p.p. for the highest value of the Gini index (red line in Fig. 3B). While these growth rate reductions may appear small, they imply that for the highest value of the Gini index output losses accumulate over three and a half decade to 16,218 US\$ per-capita, an additional 2,196 US\$ per-capita compared to the lowest value of the Gini index. The dependence of growth on shock heterogeneity can again be understood by the disproportional increase of indirect losses with shock intensity making incomplete recovery between events more likely with increasing Gini index (cf. Fig. 1A). In line with this reasoning, we find that, in the scenario without construction investment cap, where the recovery time is substantially shorter then in the scenarios with caps (cf. Fig. 1), growth losses are nearly independent of the Gini index.

Further, for each fixed level of shock heterogeneity, growth losses decrease with increasing insurance coverage which can be understood as follows: Insurance provides additional financial means for reconstruction and thereby mitigates the impact of shocks that are large compared to the reconstruction investment cap by reducing the recovery time and therefore suppressing incomplete recovery. For instance, for the standard scenario 


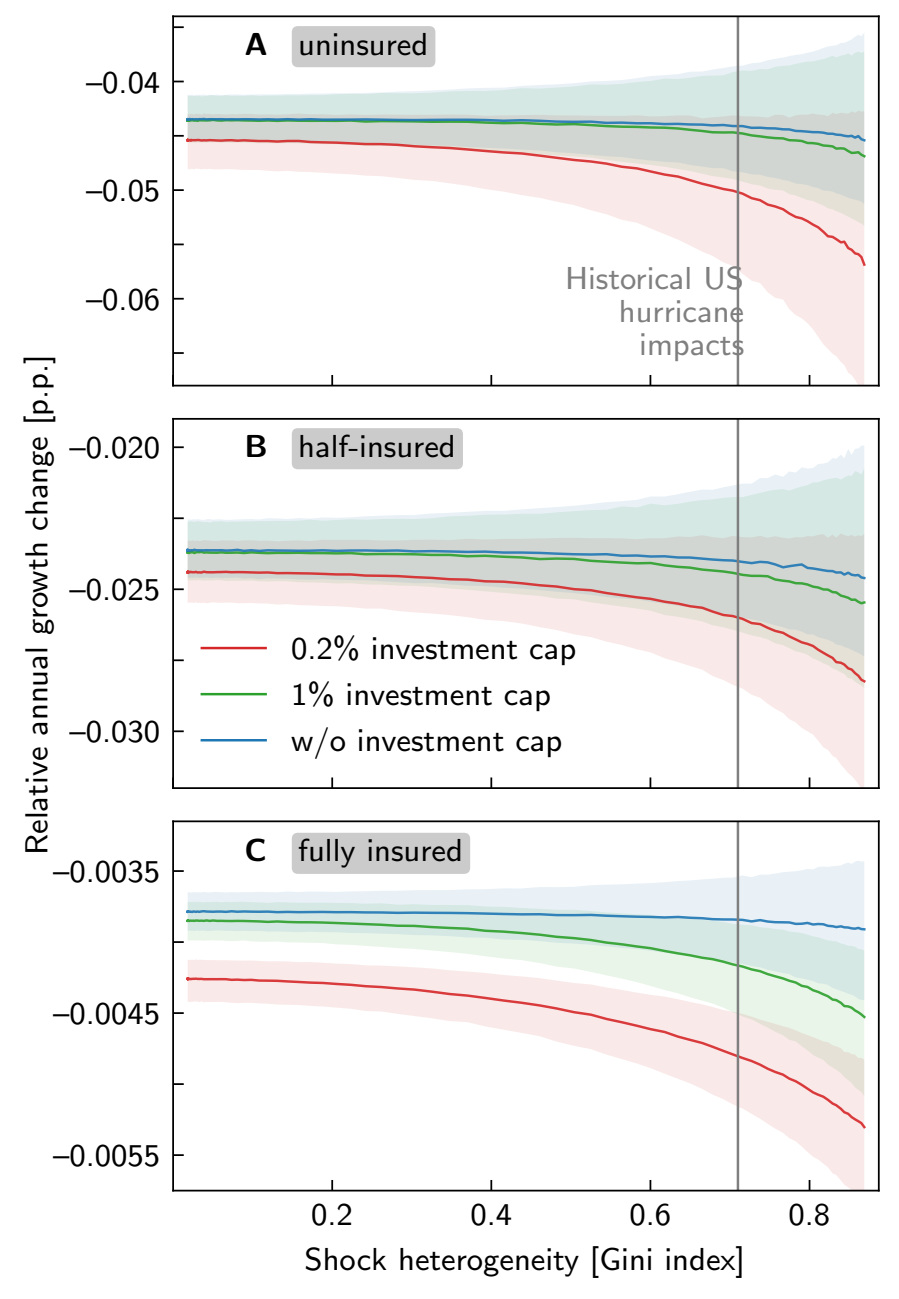

Fig. 3. Impact of hurricane shock heterogeneity on annual output growth rate. Median annual growth rate change of the economy under hurricane shocks relative to the growth rate of the corresponding unperturbed economy, as a function of shock heterogeneity - measured by the Gini index - for no (A), half (B), and full (C) insurance coverage. Blue, green, and red lines depict median growth rate changes for scenarios where reconstruction investment is not limited, limited to $0.2 \%$, and $1 \%$ of weekly output, respectively; shaded areas mark the corresponding 16.7-83.3 percentile confidence intervals. The grey vertical line indicates the median Gini index of the historical distribution of relative direct asset losses. 
and the median Gini index of the historical period (grey vertical line in Fig. 3), output losses accumulate over three and a half decades to 14,904 US $\$$ per-capita. They are therefore, on average 832 US\$ per-capita and 1,121 US\$ per-capita higher than for the corresponding scenarios with a $1 \%$ and without reconstruction investment cap, respectively.

The greatest benefit of insurance is, however, that it strongly mitigates the magnitude of growth losses. For the median Gini index of the historical period and the lowest investment cap, hurricanes reduce annual growth on average by 0.048 p.p. in the uninsured scenario. These losses are already roughly halved to 0.025 p.p. for the standard scenario with $50 \%$ insurance coverage and reduced by a magnitude larger than ten to 0.0045 p.p. in the fully insured scenario. Accordingly, output losses accumulate over three and a half decade decrease from 28,807 US\$, over 14,904 US\$, to 2,746 US\$ per-capita. Critically, there is a tradeoff between the increase in consumption in the disaster aftermath in the presence of insurance and consumption and economic growth losses due to lower capital accumulation in normal times. We find that the studied insurance scheme only fosters economic growth (supplementary Fig. S7) and national consumption when large indirect losses arise, i.e. when the reconstruction process is slow and shocks are heterogeneously distributed as this likely was the case in the historical period. Thereby, the benefit of insurance for national consumption (averaged over many shock realisations) increases with insurance penetration and shock heterogeneity (supplementary Fig. S8 and Fig. S9)). Insurance premiums increase with insurance coverage but remain small compared to average percapita consumption. For instance, for the standard scenario of $50 \%$ insurance and the mean shock heterogeneity of the historical period, mean annual insurance premiums equal 110 US\$ which is only a tiny fraction (about $0.003 \%$ ) of US households' average annual consumption in the historical period. (supplementary Fig. S10)

To set all these numbers into context, it is important to keep in mind that our model, by construction, computes growth losses borne by the US in total. Local growth losses in the affected counties may be much larger.

\section{Better insurance coverage can help mitigate climate change-induced growth losses}

To account for the substantial uncertainty on how climate change will impact on hurricane climatology, we employ two different approaches estimating climate change-induced 
changes in the return frequencies of hurricanes, one at the lower and one at the upper end of the impacts reported in the recent literature ${ }^{5}$. Both approaches consistently predict an increase of the proportion of very intense storms, though the magnitude of this change - and in consequence the resulting changes to direct asset losses - differs substantially between the two approaches. Importantly, in contrast to the last section, where only the heterogeneity of events was mutable, these climate change-induced frequency increases may additionally translate into changes of the distribution of direct asset losses with respect to i) the number of hurricanes and ii) the cumulative direct asset losses during the study period (Fig. 4) (see Methods for details). Knutson et al. report a moderate increase of the

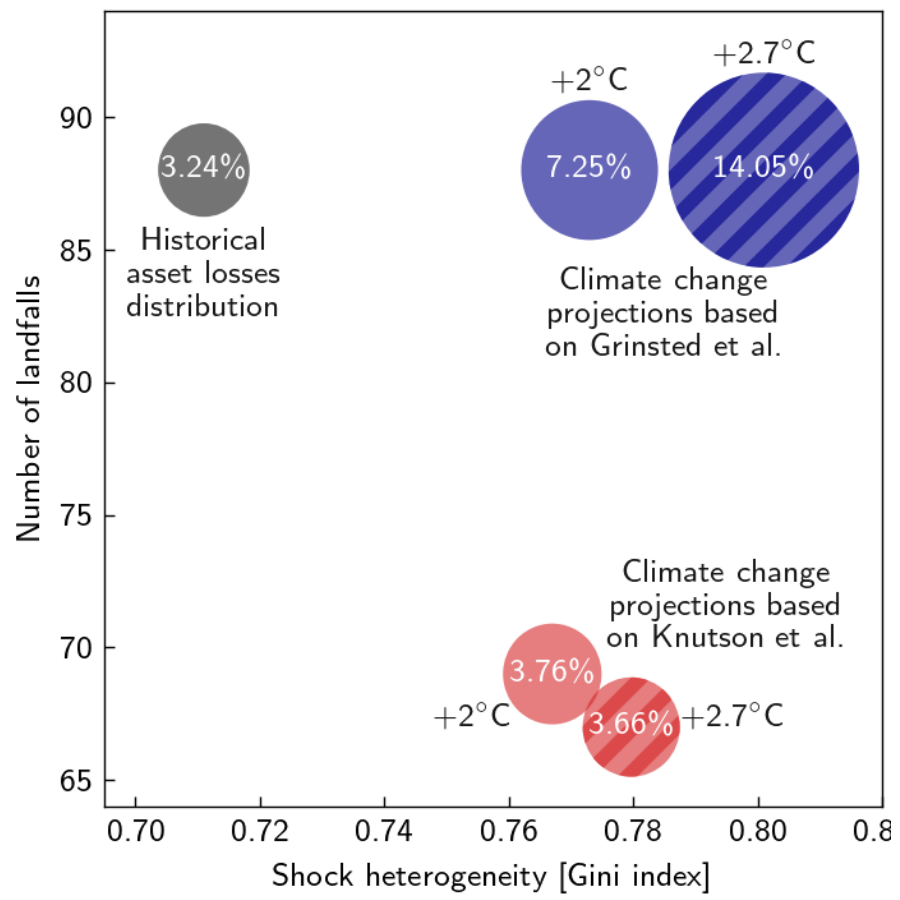

Fig. 4. Visualisation of climate changeinduced shifts of the hurricane shock distribution. Under global warming, the historical distribution of the direct asset losses caused by the $N_{s}=88$ historical hurricanes that made landfall in the US in the 35-years period from 1980 to 2014 (black filled circle) according to the NatCatSERVICE database ${ }^{1}$ is projected to change along three dimension: i) the median shock heterogeneity measured by the Gini index (x-axis), ii) the number of landfalls for a 35 years period ( $y$-axis) and iii) the median cumulative direct asset losses (size of circles). Blue and red circles indicate estimates for $+2^{\circ} \mathrm{C}$ (filled) and $+2.7^{\circ} \mathrm{C}$ (hashed) worlds (above pre-industrial levels) based on Grinsted et al. ${ }^{6}$ and Knutson et al. ${ }^{7}$, respectively. The numbers in the circles refer to the median cumulative relative asset losses for a 35 years period (see Methods for details).

return frequency of the most intense (Cat. $4-5)$ hurricanes by $45 \%$ in a $2^{\circ} \mathrm{C}$ world $\left(2.7^{\circ} \mathrm{C}\right.$ : $39 \%$ ) but a reduction of the overall number of hurricanes (of all categories) by $22 \%\left(2.7^{\circ} \mathrm{C}\right.$ : $24 \%$ ), which the authors derive from changes in the maximum lifetime wind speeds of the storms obtained from dynamical down-scaled global circulation model runs ${ }^{7}$ ("wind speed-based" estimate). In contrast, Grinsted et al. use observational storm surge data and estimate a considerable increase of relative return frequencies ranging from 1.4 fold $\left(2.7^{\circ} \mathrm{C}: 1.6\right.$ fold $)$ for storms with a small surge index to a 6.4 fold $\left(2.7^{\circ} \mathrm{C}: 15.2\right.$ fold $)$ for the 
most intense storms ${ }^{6}$ ("surge-based" estimate). The authors' statistical analyses cannot distinguish whether this frequency increase is caused by an overall increase in the number of storms or merely implies a shift of the distribution of storm surges to higher intensity events. However, since there is relatively good agreement in the literature that the average number of hurricane per season will not strongly change with global warming ${ }^{5}$, in our derivation of future direct asset losses according to Grinsted's surge-based estimate, we assume that the number of storms does not change compared to the historical study period (see Methods for details).

For both, the wind speed- and surge-based estimates, we obtain a moderate increase of shock heterogeneity with the median Gini index increasing from its historical value of 0.71 to $0.77\left(2.7^{\circ} \mathrm{C}: 0.78\right)$ and $0.77\left(2.7^{\circ} \mathrm{C}: 0.80\right)$, respectively. For the latter, the hurricane number (88) remains unchanged compared to the historical period, whereas it decreases to $69\left(2.7^{\circ} \mathrm{C}: 67\right)$ for the latter. Further, under the assumption of constant adaptation levels, the estimated cumulative relative asset losses over 35 years increase only moderately from $3.24 \%$ for the historical period to $3.76 \%\left(2.7^{\circ} \mathrm{C}\right.$ : $\left.3.66 \%\right)$ for the wind speed-based estimate but more than double $(7.25 \%)\left(2.7^{\circ} \mathrm{C}: 14.05 \%\right)$ for the surge-based estimate. In terms of median annual growth losses, we obtain a moderate increase by $10 \%$ (for $2^{\circ} \mathrm{C}$ as well as $2.7^{\circ} \mathrm{C}$ ) compared to the historical standard scenario for the wind fieldbased estimate but a strong increase by $146 \%\left(2.7^{\circ} \mathrm{C}: 522 \%\right)$ for the storm surge-based estimate (Fig. 5A). The reason is that for the former the additional growth losses due to the increases of shock heterogeneity and cumulative direct asset losses are partially compensated by the reduction of growth losses due to the reduced absolute number of hurricanes; whereas for the latter the increases of shock heterogeneity, cumulative direct asset losses, and hurricane number all enhance growth losses. Since we always consider growth losses relative to a baseline scenario with the same reconstruction investment cap (and insurance coverage), these findings are robust with regard to changes in the reconstruction investment cap (cf. Fig. 5B and Fig. 5C).

We finally address the question whether an increase in insurance coverage would be sufficient to compensate for the additional global warming-induced growth losses. We find that, to this end, the historical insurance coverage of $50 \%$ would have to be substantially raised to $84 \%\left(2.7^{\circ} \mathrm{C}\right.$ : $\left.99 \%\right)$ according to the surge-based estimate, whereas a moderate increase to $58 \%$ for $2^{\circ} \mathrm{C}$ as well as $2.7^{\circ} \mathrm{C}$ would suffice according to the wind field-based 


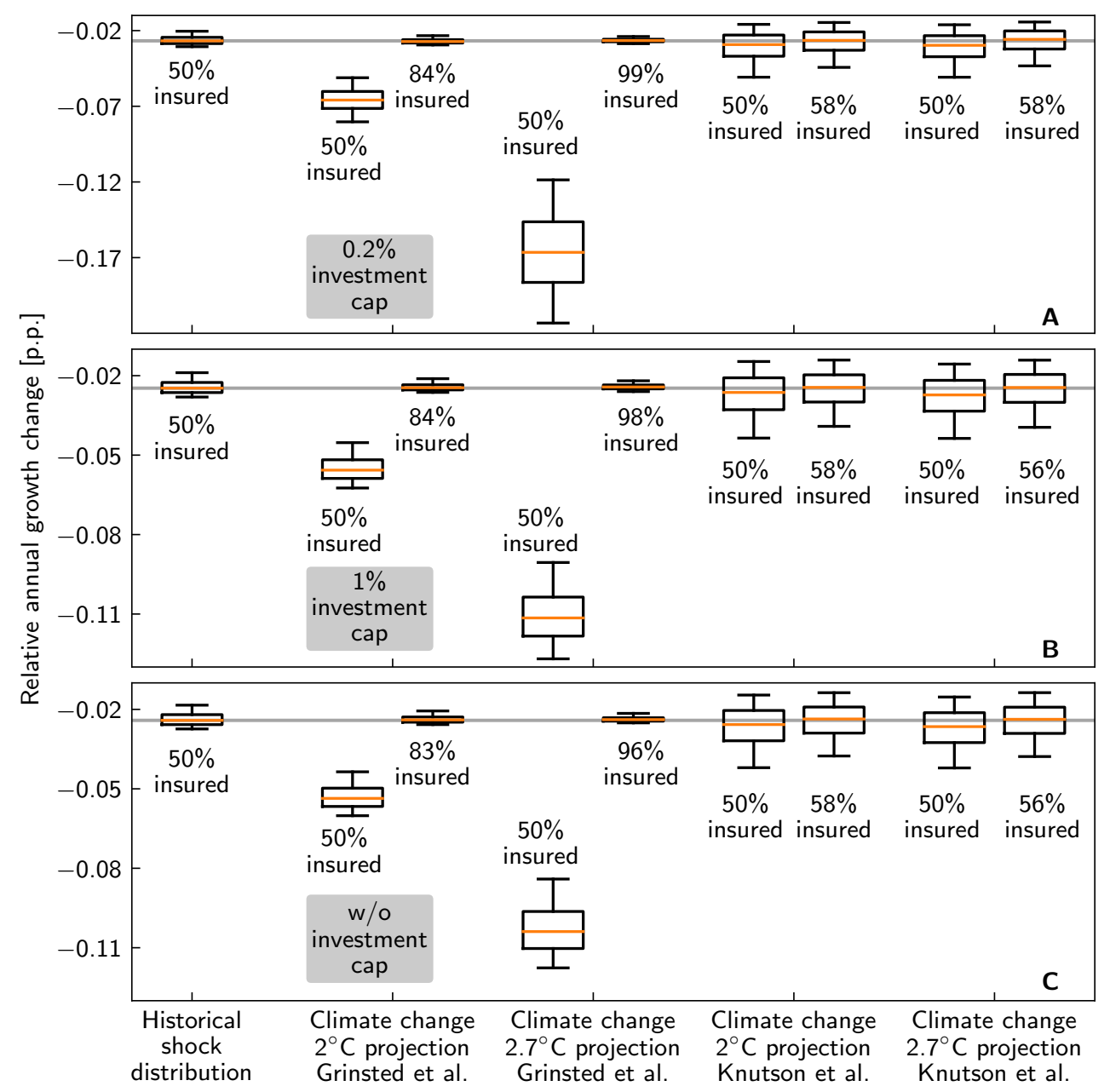

Fig. 5. Projected impacts of hurricanes on economic growth in $2^{\circ} \mathrm{C}$ and $2.7^{\circ} \mathrm{C}$ worlds and the effectiveness of insurance as coping strategy. Annual growth losses (relative to the corresponding unperturbed economies evolving on the balanced growth paths) as obtained for the historical shock distribution (50\% insurance coverage, period $1980-2014 ; 1^{\text {st }}$ column), for Paris-compatible $+2^{\circ} \mathrm{C}$ warming above pre-industrial levels $\left(2^{\text {nd }}, 3^{\text {rd }}, 6^{\text {th }}\right.$ and $7^{\text {th }}$ column) and $+2.7^{\circ} \mathrm{C}$ warming in compliance with current policies $\left(4^{\text {th }}, 5^{\text {th }}, 8^{\text {th }}\right.$ and $9^{\text {th }}$ column $)$ for reconstruction investment caps of $0.2 \%$ (A, standard scenario), $1 \%$ (B) and without reconstruction investment cap (C). Climate change projections of growth losses are derived from two different methods to estimate climate change-induced changes in the return frequencies of hurricanes by Grinsted et al. ${ }^{6}$ and Knutson et al. ${ }^{7}$ (50\% insurance coverage, $2^{\text {nd }}$ and $4^{\text {th }}$ column, respectively). Additionally, for both estimates and warming levels the insurance coverages that would be necessary to reduce growth losses to the historical level are shown $\left(3^{\text {rd }}, 5^{\text {th }}, 7^{\text {th }}\right.$ and $9^{\text {th }}$ column). Orange lines, boxes, and whiskers indicate median loss estimates as well as the $25^{\text {th }}-75^{\text {th }}$ and $5^{\text {th }}-95^{\text {th }}$ percentile ranges, respectively. 
estimate for the standard scenario (cf. columns 2 and 6 with columns 3 and $7\left(2.7^{\circ} \mathrm{C}\right.$ : 5 and 9) in Fig. 5). Again, these findings are fairly robust with regard to different values of the construction investment cap.

\section{Discussion}

These numbers suggest that a better insurance coverage could indeed be a viable means to compensate for climate change-induced increases in tropical storm-related losses, even in the absence of other adaptation measures. However, we caution that we do not account for several drivers of losses in the future projections, which may lead to an overor underestimation of future losses. On the one hand, we assume no future changes in the vulnerability of the economy to tropical cyclone impacts. While this may result in an overestimation of future losses, since vulnerability may be reduced by additional adaptation efforts, there also exists empirical evidence that the vulnerability of the US economy to tropical cyclone strikes has rather increased over the past decades ${ }^{41 ; 42}$. Assuming constant vulnerability thus provides a balanced perspective. On the other hand, our estimates of climate-induced changes in direct asset losses are based on estimates for the changes in the return frequencies of the storms only; other potential channels through which climate change may impact on the economic losses caused by tropical cyclones, such as increasing storm surge risk due to sea level rise ${ }^{43 ; 44}$, and stronger precipitation associated with hurricanes ${ }^{45}$ are neglected. Neglecting these additional drivers as well as non-economic losses such as lives lost most likely results in an underestimation of future economic losses ${ }^{46 ; 47}$

Further, using a simple macroeconomic growth model with only one homogeneous output good, our analysis cannot provide information on the recovery dynamics of individual sectors and may therefore underestimate delays arising from the scarcity of intermediate goods from strongly affected sectors needed for production in other sectors and the associated scarcity-induced price inflation in the disaster aftermath. In consequence, we may underestimate recovery costs ${ }^{48 ; 49 ; 50}$ and, in turn, growth losses. Finally, we do not discuss moral hazard issues that may arise from the considered mandatory precautionary savings scheme and may require the introduction of deductibles, for instance, to deincentive the construction of new buildings in storm-surge prone locations ${ }^{51}$. This might 
provide an over-optimistic assessment of the efficacy of insurance in mitigating disaster losses.

Our research stresses the importance of non-linear economic responses to consecutive extreme weather events. In particular, our results suggest that only by i) resolving the response to individual events, and by ii) accounting for a realistic timing of the events (e.g., accounting for the hurricane season), it is possible to estimate the full economic impact of extreme events ${ }^{23}$. Further, these findings are key to assess the efficacy of adaptation and coping strategies. For instance, in our study the limited pace of insurance payouts delays reconstruction efforts in the disaster aftermath, but a similar reasoning holds for physical protection measures, which once damaged may take months or even years to be repaired ${ }^{52}$. Thus, temporally resolving the economic recovery phase is critical for the assessment and comparison of disaster response measures. This aspect becomes especially important since extreme weather events are projected to intensify and become more frequent with global warming, at least on a regional level ${ }^{53}$. In this regard, our findings may also encourage the climate integrated assessment modelling community to consider new approaches allowing to go beyond smooth damage functions translating changes in global mean temperature into aggregate output losses. As shown here, this common approach may underestimate the economic repercussions of extreme weather events since it neglects potentially important non-linearities in the economic response such as the disproportional increases of indirect losses with impact intensity or the case of incomplete recovery ${ }^{23}$. This may also explain the discrepancy between the loss estimates reported in the recent climate econometrics literature and the estimates of climate integrated assessment models.

While our estimates on how climate change may impact on economic losses caused by hurricanes in the US are subject to several sources of uncertainty, they nonetheless show that the mitigating effect of increased insurance coverage is of the same order of magnitude as the climate change-induced loss increase. Though insurance premiums may increase under global warming by up to a factor of four, they likely will remain affordable for US consumers. This suggests that insurance can be a major building block of future climate change adaptation strategies, at least in developed countries. For developing countries the hurdles to adapt to climate change are much higher since they are often more strongly affected by - and more vulnerable to - climate change impacts and lack the 
financial means and strong institutions to implement comprehensive climate adaptation measures ${ }^{54}$. To illustrate this, we have analysed the tropical cyclone-prone Small Island Developing State of Haiti (Sec. B.2) and find that the tropical cyclone induced growth losses it suffers in the present climate are already by one magnitude larger than those of the US (cf. Fig. 3B with Fig. S12A). One reason is that Haiti's disaster insurance market is much less developed and nearly all of the past tropical cyclone losses were not insured ${ }^{1}$. Further, already in the present climate Haiti is affected so strongly that even in the idealistic limit of full insurance coverage, it would still suffer growth losses comparable in magnitude to those of the US today (cf. Fig. 3B with Fig. S12C), and tropical cyclone impacts are projected to further aggravate for Haiti under continued climate change (appendix B.2.1). To this end, our results stress the importance - for developing and developed countries alike - to complement insurance solutions with other measures to build resilience to extreme weather events such as investments into better housing standards and resilient infrastructure $55 ; 56$ or coping strategies such as managed retreat ${ }^{57 ; 58}$ in a risk-layering approach ${ }^{59}$. However, in contrast to rich developed countries of the Global North, strongly affected developing countries will be only able to successfully adapt to climate change impacts when national and international mechanisms and institutions providing concessional climate finance and expertise in climate adaptation such as the United Nations' Green Climate Fund are further strengthened by ensuring that they have both, the financial resources and the effective government, to fulfil their mandates. 


\section{A Methods}

\section{A.1 Modeling approach}

As the standard neoclassical Solow-Swan growth model for a closed economy ${ }^{60}$, our model InGroCIIM (Insured Growth under Climate Impacts) describes the growth of a percapita stock of physical capital $k$ for a unique indistinguishable good under investments and capital depreciation. Here, we neglect changes in labour market and population growth as drivers of capital growth. In extension to the standard model, we account for a non-profit insurance scheme and obtain two coupled differential equations for $k$ and the per-capita capital stock of the insurance $k_{\text {l }}$ reading

$$
\begin{aligned}
\dot{A}(t) & =\wedge A(t), \\
\dot{k}(t) & =s y(t)-\left[\delta+r_{l}\right] k(t)+F_{l}(t), \\
\dot{k}_{l}(t) & =r_{l} k(t)-F_{l}(t) .
\end{aligned}
$$

Here, $(\cdot)$ denotes the derivative with respect to time $t$. We assume that total factor productivity (TFP) $A$ growth exponentially with trend growth rate $\Lambda$, and $s, y$, and $\delta$ denote savings rate, production function, and depreciation rate of capital, respectively. The insurance premium $r_{I} \equiv r_{l}\left(r_{c}\right)$ depends on the economy's insurance coverage $r_{c}$, and $F_{l}(t)$ denotes the insurance payouts in the disaster aftermaths. Both terms are detailed below. Further, we assume that the production process can be described by a Cobb-Douglas production function $y(t) \equiv A(t) k(t)^{\alpha}$, where $\alpha \in(0,1]$ denotes the capital share of income. We model the impact of extreme weather events as shocks to the capital stock. Following ${ }^{29}$, we describe the economic recovery in the disaster aftermath as the superposition of two different mechanisms: i) a fast reconstruction process of the damaged capital and ii) the comparably slow growth of the capital stock due to technological development. To this end, we write the capital stock as the product of the fraction of remaining production capacity $\xi(t) \in[0,1]$ and a "potential capital stock" $k_{p}$,

$$
k(t) \equiv \xi(t) k_{p}(t)
$$


By employing Eqs. (2), (3) and (4), we may then rewrite the dynamical equation for the capital stock (1b) as

$$
y\left(t_{s}\right)=\xi\left(t_{s}\right) \lim _{t \nearrow t_{s}}[y(t)]=\xi\left(t_{s}\right) A\left(k_{p}\left(t_{s}\right)\right)^{\alpha},
$$

where $\xi\left(t_{s}\right)<1$, and $k_{p}\left(t_{s}\right)$ represents the pre-disaster value of the capital stock. Thus, production is reduced by the same factor $1-\xi(t)$ as the capital stock, i.e. direct asset losses equal direct production losses, and the marginal productivity of capital remains unchanged.

To derive the dynamical equations for $k_{p}$ and $\xi$, we first decompose total investment $I(t)$ into the sum of two different investment channels: short-term reconstruction investments $I_{\xi}(t)$, and regular investments increasing production capacity $I_{k}(t)$,

$$
I(t) \equiv s y(t)+F_{l}(t)=I_{k}(t)+I_{\xi}(t)
$$

$$
\begin{aligned}
\left(\xi(t) k_{p}(t)\right) & =\dot{\xi}(t) k_{p}(t)+\xi(t) \dot{k}_{p}(t) \\
& =I_{k}(t)+I_{\xi}-\left[\delta+r_{l}\right] \xi(t) k_{p}(t) .
\end{aligned}
$$


By comparing the right-hand sides of Eqs. (5a) and (5b), we obtain the dynamical equations for $k_{p}$ and $\xi$ as

$$
\begin{aligned}
\dot{k}_{p}(t) & =\frac{I_{k}(t)}{\xi(t)}-\left[\delta+r_{\imath}\right] k_{p}(t), \\
\dot{\xi}(t) & =\frac{I_{\xi}(t)}{k_{p}(t)} .
\end{aligned}
$$

Next, we derive an expression for $I_{\mathcal{\xi}}(t)$ which then permits us to calculate $I_{k}$ from Eq. (4). To this end, we have to make four assumptions: First, we assume that reconstruction investments yield higher returns compared to investments in the potential capital stock and are therefore prioritised. Second, we assume that reconstruction efforts are limited by shortterm constraints such as a lack of skilled labour or reconstruction materials, which may significantly slow down the economic recovery. In consequence, only a fraction $f_{\max } \in[0,1]$ of the output available for investment $s y(t)$ can be used to finance reconstruction; the actual value of the investment cap $f_{\max }$ depends upon the economy under consideration ${ }^{30}$. Third, we assume that reconstruction efforts cease when the capital stock equals the potential capital stock, no overshoot is possible. Fourth, we assume that the insurance primarily finances reconstruction efforts. In the presence of insurance, the investment cap may be temporarily exceeded since the insurance provides additional financial means, e.g., to compensate for scarcity driven wage increases ${ }^{34}$. This assumption is motivated by empirical findings that higher insurance coverage can lead to a faster economic recovery ${ }^{32 ; 33}$. However, if reconstruction is completed before all of the insured capital is reimbursed, the remaining insurance payout will be invested into the potential capital stock. With these assumption, we may express $I_{\xi}(t)$ as

$$
I_{\xi}(t) \equiv \begin{cases}0 & \xi(t)=1, \\ \min \left[\min \left[f_{\max }, s\right] y(t)+F_{l}(t), I_{r}(t)\right] & \xi(t)<1,\end{cases}
$$

where $I_{r}(t) \equiv(1-\xi(t)) k_{p}(t)$ is the investment needed to reconstruct the capital stock in the present time step. 


\section{A.1.1 Insurance payout dynamics}

We model insurance as a compulsory precautionary savings mechanism which may be implemented and managed on the national level by a public institution. To our knowledge, there are no empirical data on the payout dynamics of such an insurance scheme in the US. This is why we use observational data of insurance payouts of commercial providers of risk diversifying insurance by the Reinsurance Association of America (RAA) ${ }^{31}$ arguing that the payouts dynamics of the insurance scheme discussed here and commercial (re-) insurers may be similar as main processing steps such as the filing of insurance claims and their eligibility assessment by the insurance provider would be identical for both insurance schemes. According to the RAA data, the reimbursement of insured losses $f_{l}(t)$ can spread over several years; $60 \%$ (90\%) of the insured values are reimbursed with in one (three) year(s). This may significantly delay the reconstruction process. We describe the cumulative insurance payouts with a sigmoidal function,

$$
f_{l}\left(t-t_{s} ; r_{c} \Delta_{s} k_{p}\left(t_{s}\right)\right) \equiv r_{c} \Delta_{s} k_{p}\left(t_{s}\right) \beta \frac{\left(\frac{t-t_{s}}{\tau_{l}}\right)^{\beta-1}(a-1) \exp \left[-\left(\frac{t-t_{s}}{\tau_{l}}\right)^{\beta}\right]}{\tau_{l}\left(1+(a-1) \exp \left[-\left(\frac{t-t_{s}}{\tau_{l}}\right)^{\beta}\right]\right)^{2}}, \quad \forall t>t_{s}
$$

Here, $t_{s}$ denotes the time of the shock, the insured losses are given by the product of the insurance coverage $r_{C}$, the asset loss $\Delta_{S}$ at time $t_{s}$ relative to the pre-shock potential capital stock $k_{p}\left(t_{s}\right)^{1}$. The three parameters $a, \tau_{l}$ and $\beta^{31}$ are specified in Tbl. 1 (see supplementary Fig. S2 for a fit of the observational data). The cumulative insurance payout in response to multiple successive asset losses $\left\{\Delta_{s_{i}}\right\}_{i}$ at times $\left\{t_{s_{i}}\right\}_{i}$ are then given by the sum of the individual payouts

$$
F_{l}\left(t ;\left\{t_{s_{i}}\right\}_{i},\left\{\Delta_{s_{i}}\right\}_{i}\right) \equiv \sum_{i=1}^{N_{s}} f_{l}\left(t-t_{s_{i}} ; r_{c} \Delta_{s_{i}} k_{p}\left(t_{s_{i}}\right)\right)
$$

where index $i$ labels the shock number, and $N_{s}$ denotes the total number of shocks.

\footnotetext{
${ }^{1}$ It is worthy to note, that according to Eq. (3) this is identical to expressing asset losses relative to the output in the year before the shock as done for the calibration of the model to empirical data in Sec. A.1.2
} 


\section{A.1.2 Model calibration}

We assume that, in the absence of shocks, the economy evolves along its balanced growth path (BGP), where output growth is constant and only driven by TFP growth (growth rate $\Lambda)$,

$$
g \equiv \frac{\dot{y}}{y}=\frac{\dot{A}}{A}+\alpha \frac{\dot{k}}{k}=\Lambda+\alpha g \quad \Leftrightarrow \quad \Lambda=(1-\alpha) g,
$$

where we have used in the second identity that if $y$ growth constantly with rate $g, k$ also growth constantly with the same rate ${ }^{2}$. Since in the absence of shocks $F_{l}(t)=0 \quad \forall t \in$ $[0, \mathcal{T}]$, where $\mathcal{T}$ denotes the length of the simulation, the dynamic equations for $k$ and

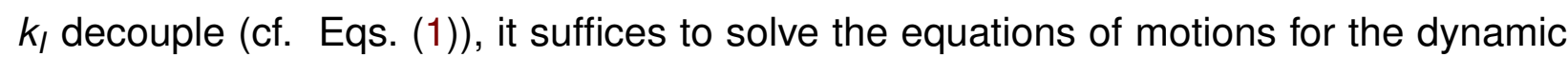
variables $A$ and $k$ along the BGP. The corresponding equation for $k_{\text {/ }}$ can then be derived from Eq. (1c). To this end, we insert the coordinate transformation

$$
A(t)=e^{\wedge t} \tilde{A}(t) \quad \& \quad k(t)=e^{g t} \tilde{k}(t),
$$

into the dynamic equations for $A$ and $k$ yielding,

$$
\begin{aligned}
& \dot{\tilde{A}}(t)=0, \\
& \dot{\tilde{k}}(t)=s \tilde{y}(t)-\left(\delta+r_{l}+g\right) \tilde{k}(t),
\end{aligned}
$$

where we have introduced the output in BGP coordinates $\tilde{y}(t) \equiv A^{0} \tilde{k}^{\alpha}(t)$. Equating the right-hand-sides of Eqs. (8) to zero, yields the steady states for $A$ and $k$ in BGP coordinates

$$
\tilde{A}^{\star}=A^{0}, \quad \& \quad \tilde{k}^{\star}=k^{0}=\left(\frac{s A^{0}}{\delta+r_{l}+g}\right)^{\frac{1}{1-\alpha}},
$$

where $(\cdot)^{\star}$ and $k^{0}$ denote the steady state values of variables and $k^{0}$ initial capital stock, respectively. This allows to write the BGP solution of Eqs. (1) as

$$
A(t)=e^{\wedge t} A^{0}, \quad k(t)=e^{g t} k^{0}, \quad k_{l}(t)=\frac{r_{I}}{g}\left[k(t)-k^{0}\right]=\frac{r_{l}}{g} k^{0}\left[e^{g t}-1\right] .
$$

\footnotetext{
${ }^{2}$ This can be seen as follows: From the first identity in Eq. (7), it follows that the growth rate of the capital stock $\frac{k}{k}=\frac{g-\Lambda}{\alpha}$ is constant when $g$ is constant. From Eq. (2) it then follows that $k$ and $y$ have to grow with the same rate $g$.
} 
$k^{0}=s y^{0}\left(\delta+r_{l}+g\right)^{-1}$, respectively. Table 1 lists all exogenous parameters used in the simulations. It is worthy to note that

\begin{tabular}{lccr} 
Quantity & Symbol & Value & Unit \\
\hline Initial GDP per capita & $y^{0}$ & 51638.1 & US\$ \\
GDP growth rate & $g$ & $2.6 \%$ & year $^{-1}$ \\
Savings rate & $s$ & 0.2 & year $^{-1}$ \\
Capital depreciation rate & $\delta$ & 0.1 & year $^{-1}$ \\
Capital share of income & $\alpha$ & 0.7 & \\
Time step length & $\Delta t$ & $\frac{1}{52}$ & year \\
\hline Insurance payout parameter one & $a$ & $10^{9}$ & \\
Insurance payout parameter two & $\beta$ & 0.0741 & \\
Insurance payout parameter three & $\tau_{I}$ & $1.31 \cdot 10^{-18}$ & year \\
Empirical insurance premium coefficient & $\varepsilon$ & $4.046 \cdot 10^{-4}$ & \\
\hline Simulation period & $\mathcal{T}$ & 35 & year \\
Cumulative relative historical asset losses & $\Delta_{\mathcal{T}}$ & 3.24 & \% \\
Number of historical landfalling hurricanes & $N_{s}$ & 88 & \\
Standard deviation of historical & & & \\
log-normal asset loss distribution & $\sigma_{0}$ & 0.10654 & \\
\hline
\end{tabular}

Tbl. 1. Exogenous parameters used in the numerical simulations.

calibrate the model to the US, we set initial per-capita annual output $y^{0}$ and output growth rate $g$ to the per-capita growth domestic product (GDP) and the GDP growth rate of the US in 2015 according to the World Banks' and OECD's National Accounts database ${ }^{3}$, whereas capital depreciation rate $\delta$, savings rate $s$, and capital share of income $\alpha$ are set to their standard values for developed economies ${ }^{60}$. Using the Cobb-Douglas relation for the production function $y=A k^{\alpha}$ and the steady state relation for $k^{0}$ (cf. Eq. (9)) then allows to express initial TFP and initial per-capita stock as $A^{0}=y^{0}\left(\frac{\delta+r_{l}+g}{s}\right)^{\alpha}$ and

our model results are very robust with regard to changes of the GDP growth rate $g$ since we only consider changes of the perturbed economy relative to an unperturbed economy evolving along the BGP. Even large variations of $g \in[0.2 \%, 4 \%]$ result in changes of growth losses that are small compared to the climate uncertainties (cp. lines and shaded areas in supplementary Fig. S6)

\footnotetext{
${ }^{3}$ https://data.worldbank.org/indicator/NY.GDP.PCAP.CD
} 
Modelling a non-profit insurance scheme, we have to ensure that, averaged over many realisations, the insurance does neither make profit nor losses. However, deriving an exact analytical formula for the corresponding insurance premium $r_{l}$ is challenging since - as output losses and growth losses - it would depend upon shock heterogeneity. Instead, we here motivate a simple heuristic formula neglecting this dependence and show that the resulting average insurance profits or losses are negligible compared to the cumulative payouts of the insurance. In the worst case, the total relative asset losses occur at the last time step of the simulation. Covering this loss would require an insurance capital stock of $k_{l}(\mathcal{T})=r_{c} \Delta_{\mathcal{T}} k(\mathcal{T})$, where $\mathcal{T}$ denotes the length of the simulation. Inserting this relation in the BGP solution for $k_{l}$ (cf. Eq. (10)) provides us with the following expression for the insurance premium

$$
r_{l} \equiv \varepsilon \frac{g r_{c}}{1-e^{-g \mathcal{T}}}
$$

where we have added an empirically determined factor $\varepsilon$ ensuring that average insurance profits (or losses) are negligible. (cf. supplementary Fig. S4 revealing that average profits or losses of the insurance are about five magnitudes smaller than the insured capital.

\section{A.2 Gini index as measure for shock heterogeneity}

We fit the relative asset losses of the $N_{s}=88$ historical hurricanes with landfall included in the NatCatSERVICE database ${ }^{1}$ (cf. Tbl. S1) with a log-normal distribution (supplementary Fig. S3) with standard deviation $\sigma_{0}$. To change the heterogeneity of the loss events, we vary the standard deviation $\sigma$ of the log-normal distribution from $\frac{\sigma_{0}}{100}$ to $4 \sigma_{0}$. We use the Gini index $G \equiv \frac{L_{e}-L_{i}}{L_{e}} \in[0,1]$ as measure for the shock heterogeneity, which is derived from the difference of the areas below the Lorenz-curves for a uniform distribution $L_{e}$ and the given shock distribution $L_{i}$ (cf. Fig. 2). Shock heterogeneity increases from small to large values of the Gini index. Noteworthy, the Gini index of the historical timeseries of hurricanes with landfall equals 0.829 , whereas the median Gini index of the historical shock distribution - obtained by averaging over many synthetic realisations of asset loss time series (see Sec. A.3 for details) - equals 0.71 . 


\section{A.3 Generation of synthetic time series of asset losses}

In this section, we discuss the generation of synthetic time series of asset losses from their historical distribution as reported by the NatCatSERVICE ${ }^{1}$ and TCE-DAT databases ${ }^{63}$. For the study period 1980-2014 of $\mathcal{T}=35$ years, these databases list $N_{s}=88$ hurricanes with landfall that have caused asset losses corresponding to at least $10^{-4} \%$ of the GDP in the year of their landfall (see supplementary Tbl. S1). Over this period, relative asset losses accumulated to $\Delta_{\mathcal{T}}=3.24 \%$. We generate synthetic time series of asset losses of length $\mathcal{T}$ keeping $N_{S}$ and $\Delta_{\mathcal{T}}$ at their historical values in three steps illustrated in supplementary Fig. S5. First, following ref. ${ }^{35}$, we assume that the number of hurricanes with landfall $n_{a}$ in each season $a$ is Poisson distributed, $f_{\mathrm{P}}\left(n_{a}\right) \equiv \frac{\lambda^{n_{a}} e^{-\lambda}}{n_{a} !}$. Further, we assume that the mean number of landfalls per season $\lambda$ is constant over the study period $\mathcal{T}$. To ensure that each synthetic track contains exactly $N_{s}$ shocks, the shock number for the last season of the track is set to the remainder of available shocks $N_{s}-\sum_{a=1}^{\mathcal{T}-1} n_{a}$. To avoid that the last season always receives the remainder of available shocks, seasons are shuffled afterwards. Second, we assume that for each day of the season the likelihood of a hurricane making landfall is the same, but exclude the possibility that two hurricanes make landfall at the same day. Third, following ref. ${ }^{36}$ (cf. Fig. S3 in SI), we assume that relative asset losses $\Delta_{S}$ are log-normally distributed, $f_{\mathrm{LN}}\left(\Delta_{S}\right) \equiv \frac{1}{s \Delta_{s} \sqrt{2 \pi}} \exp \left[-\frac{\left(\ln \left(\Delta_{S}\right)-m\right)^{2}}{2 s^{2}}\right]$, where we have introduced the parameters $s \equiv\left(\ln \left(\frac{\sigma^{2}}{\frac{\Delta_{\mathcal{T}}{ }^{2}}{N_{s}}}+1\right)\right)^{\frac{1}{2}}, m \equiv \ln \left(\frac{\Delta_{\mathcal{T}}}{N_{s}}\right)-\frac{s^{2}}{2}$, and the standard deviation $\sigma$ of the log-normal distribution. Similarly, to step one the size of the last shock of each realisation is set to the difference between $\Delta_{\mathcal{T}}$ and cumulative relative asset losses before the last shock in order to ensure that total cumulative relative asset losses equal $\Delta_{\mathcal{T}} ;$ then shock sizes are reshuffled.

\section{A.4 Storm surge- and wind field-based climate change projections of asset losses}

Storm surge-based projections of asset losses. Grinsted et al. ${ }^{6}$ estimated the relative increase in the return frequency of hurricanes with landfall in dependence of the severity of their storm surge (measured by the surge inde ${ }^{64}$ ) per degree of global mean temperature 
(GMT) warming relative to the reference period 1980-2000. We employ these findings to project asset losses for $\mathrm{a}+2^{\circ} \mathrm{C}$ increase of GMT above its pre-industrial level ${ }^{4}$. To this end, we first map the surge indices $\left\{\int_{s_{i}}\right\}$ of the $N_{s}=88$ historical hurricanes that made landfall in the US between 1980-2014 to the corresponding relative asset losses $\left\{\Delta_{S_{i}}^{h}\right\}$ reported in the NatCatSERVICE database ${ }^{1}$ (supplementary Tbl. S1). Next, we determine the statistical correlation between historical asset losses and surge indices, yielding the damage function $f(s)$ (supplementary Fig. S11). As discussed in the main text, we assume that the average number of hurricanes with landfall will not change compared to the historical study period. In consequence, we interpret the increases in return frequency reported by Grinsted et al. as increases solely in storm surge intensity, and not as an increase of the average number of hurricanes making landfall (in each season). This allows us to map the set of historical sure indices $\left\{\int_{s_{i}}\right\}$ to a set of estimated surge indices in a $+2^{\circ} \mathrm{C}$ world $\left\{\int_{s_{i}}^{c c}\right\}$. We then assume that each future relative asset loss $\Delta_{s_{i}}^{c c}$ can be written in terms of the corresponding historical asset loss. This allows to express future relative asset losses in terms of the historical relative asset losses as well as future and historical storm surge indices,

$$
\Delta_{s_{i}}^{c c} \equiv \Delta_{s_{i}}+f\left(\int_{i}^{c c}\right)-f\left(\int_{i}^{h}\right) .
$$

Note that with this relationship historical asset losses are reproduced for $\int_{i}^{c c}=\int_{i}$. Employing Eq. (11), we project relative asset losses $\Delta_{\mathcal{T}}$ accumulated over $\mathcal{T}=35$ years to increase substantially from their historical value of $3.24 \%$ to $7.25 \%$. We then generate synthetic realisations of future asset loss time series by distributing the projected $N_{S}=88$ relative asset losses over the simulation time of $\mathcal{T}=35$ years as described in Sec. A.3.

Wind field-based projections of asset losses. Knutson et al. ${ }^{7}$ analysed an ensemble of downscaled global climate models participating in the $5^{\text {th }}$ phase of the Coupled Model Intercomparison Project (CMIP5). Based on the wind fields of the storms they estimated a median decrease of $22 \%$ in the overall number of all hurricanes but a median increase of the most intense Category 4 and 5 storms by $45 \%$ for an increase of GMT by $+2{ }^{\circ} \mathrm{C}$ above its pre-industrial level under the Representative Concentration Pathway (RCP) 4.5. To estimate the associated changes in asset losses, we first divide the $N_{s}=88$ historical

\footnotetext{
${ }^{4}$ Note that one degree of global warming compared to $1980-2000$ corresponds to $1.5^{\circ} \mathrm{C}$ of warming compared to the pre-industrial level ${ }^{65}$
} 
hurricanes that made landfall in the US in the period 1980-2014 into moderate (Category 0-3, 66 storms) and intense (Category 4-5, 22 storms) storms based on the IBTRaCS database ${ }^{66}$. Applying then the estimates of Knutson et al., we project that in $\mathrm{a}+2^{\circ} \mathrm{C}$ degree world the number of all hurricanes and the number of moderate hurricanes decrease to 69 and 37, respectively, whereas the number of intense hurricanes increase to 32 . This would lead to a minor change of relative cumulative asset losses $\Delta_{\mathcal{T}}$ from their historical value of $3.24 \%$ to $3.75 \%$. Synthetic time series of future asset losses are finally generated as described for the surge-based estimate.

\section{Code availability}

The implementation of the InGroCIIM model is openly available on github (https: //github. com/kuhla/InGroClIm or as zenodo repository 10.5281/zenodo.5017904).

\section{Data availability}

The authors thank Munich Re's NatCatSERVICE for providing assess to their natural catastrophes data base from which the direct asset losses of hurricanes with landfall and the insurance coverage employed in this study are derived. These data may be made available by the corresponding author upon request and after consultations with MunichRE. The InGroCIIM model is driven by asset losses of hurricanes with landfall relative to the growth domestic product of the US in the year of landfall as provided by the World Banks' and OECD's National Accounts database (https://data. worldbank. org/indicator/NY. GDP. PCAP.CD) (see supplementary Figs. Fig. S3 and Fig. S11). Intensities of the historical hurricanes on the Saffir-Simpsons scale are taken from the IBTRaCS database ${ }^{66}$.

\section{Acknowledgments}

This research has received funding from the German Academic Scholarship Foundation and the German Federal Ministry of Education and Research (BMBF) under the research QUIDIC (01LP1907A), and SLICE (FKZ: 01LA1829A), as well as from the Leibniz foundation under the research project ENGAGE (SAW-2016-PIK-1) and the ERA4CS Joint 


\section{Competing Interests}

537 The authors declare that they have no competing interests. 


\section{References}

[1] NatCatSERVICE Natural catastrophe know-how for risk management and research (2016). URL https://www.munichre.com/site/corporate/get/ documents_E673778764/mr/assetpool.shared/Documents/0_Corporate_Website/ Publications/302-06733_en.pdf.

[2] Krichene, H. et al. The Impacts of Tropical Cyclones and Fluvial Floods on Economic Growth - Empirical Evidence on Transmission Channels at Different Levels of Development. World Development 144, 105475 (2021). 10.1016/j.worlddev.2021.105475.

[3] Berlemann, M. \& Wenzel, D. Hurricanes, economic growth and transmission channels: Empirical evidence for countries on differing levels of development. World Development 105, 231-247 (2018). URL https://www. sciencedirect. com/science/article/abs/pii/S0305750X17304138. 10.1016/J.WORLDDEV.2017.12.020.

[4] Hsiang, S. M. \& Jina, A. S. The causal effect of environmental catastrophe on long-run economic growth: Evidence from 6,700 cyclones. Tech. Rep., National Bureau of Economic Research (2014).

[5] Knutson, T. et al. Tropical cyclones and climate change assessment. Bulletin of the American Meteorological Society $\quad 100, \quad 1987-2007 \quad$ (2019). 10.1175/BAMS-D-18-0189.1.

[6] Grinsted, A., Moore, J. C. \& Jevrejeva, S. Projected Atlantic hurricane surge threat from rising temperatures. Proceedings of the National Academy of Sciences of the United States of America 110, 5369-5373 (2013). 10.1073/pnas.1209980110.

[7] Knutson, T. R. et al. Dynamical downscaling projections of twenty-first-century atlantic hurricane activity: CMIP3 and CMIP5 model-based scenarios. Journal of Climate 26, 6591-6617 (2013). 10.1175/JCLI-D-12-00539.1.

[8] Saffir-Simpson Hurricane Wind Scale. URL https://www.nhc. noaa.gov/aboutsshws. php. 
[9] Pielke, R. A. et al. Normalized Hurricane Damage in the United States: 1900-2005. Natural Hazards Review 9, 29-42 (2008). 10.1061/(asce)1527-6988(2008)9:1(29).

[10] de Ruiter, M. C. et al. Why We Can No Longer Ignore Consecutive Disasters. Earth's Future 8 (2020). 10.1029/2019EF001425.

[11] Raymond, C. et al. Understanding and managing connected extreme events. Nature Climate Change 10, 611-621 (2020). 10.1038/s41558-020-0790-4.

[12] Kousky, C. The Role of Natural Disaster Insurance in Recovery and Risk Reduction. Annual Review of Resource Economics 11, 399-418 (2019). 10.1146/annurevresource-100518-094028.

[13] Botzen, W. J., Kunreuther, H. \& Michel-Kerjan, E. Protecting against disaster risks: Why insurance and prevention may be complements. Journal of Risk and Uncertainty 59, 151-169 (2019). 10.1007/s11166-019-09312-6.

[14] Peter, G. V., Dahlen, S. V. \& Saxena, S. Unmitigated disasters? New evidence on the macroeconomic cost of natural catastrophes (2012).

[15] Michel-Kerjan, E. \& Kunreuther, H. Redesigning flood insurance (2011). 10.1126/science.1202616.

[16] Arena, M. Does Insurance Market Activity Promote Economic Growth ? A Cross-Country Study for Industrialized and Developing Countries. The journal of Risk and Insurance $\quad 75, \quad 921-946 \quad$ (2008). URL https: //www.jstor.org/stable/25145316.

[17] Calliari, E., Surminski, S. \& Mysiak, J. The Politics of the UNFCCC's Loss and Damage (Springer, 2019). 10.1007/978-3-319-72026-5_6.

[18] Krieger, K. \& Demeritt, D. Limits of insurance as risk governance Market failures and disaster politics in German and British private flood insurance (2015). URL https: //www.lse.ac.uk/accounting/assets/CARR/documents/D-P/Disspaper80.pdf.

[19] Charpentier, A. Insurability of climate risks. Geneva Papers on Risk and Insurance: Issues and Practice 33，91-109 (2008). 10.1057/palgrave.gpp.2510155. 
[20] Rose, S. K., Diaz, D. B. \& Blanford, G. J. Understanding the social cost of carbon: A model diagnostic and inter-comparison study. Climate Change Economics 8 (2017). 10.1142/S2010007817500099.

[21] Ortiz, R. A. \& Markandya, A. Integrated Impact Assessment Models of Climate Change with an Emphasis on Damage Functions: a Literature Review. Basque Centre for Climate Change 1-35 (2009). URL http://ideas.repec.org/ p/bcc/wpaper/2009-06.html\#download.

[22] Nordhaus, W. D. The Climate Casino: Risk, Uncertainty, and Economics for a Warming World (Yale University Press, 2013).

[23] Otto, C., Piontek, F., Kalkuhl, M. \& Frieler, K. Event-based models to understand the scale of the impact of extremes. Nature Energy 5, 111-114 (2020). 10.1038/s41560020-0562-4.

[24] Pindyck, R. S. The use and misuse of models for climate policy. $\quad$ Review of Environmental Economics and Policy 11, 100-114 (2017). 10.1093/reep/rew012.

[25] Farmer, J. D., Hepburn, C., Mealy, P. \& Teytelboym, A. A Third Wave in the Economics of Climate Change. Environmental and Resource Economics 62, 329-357 (2015). 10.1007/s10640-015-9965-2.

[26] Pindyck, R. S. Pricing Carbon When We Don't Know the Right Price. Energy \& Environment 87, 166-167 (2013). 10.1089/acm.2010.0309.

[27] Carleton, T. \& Hsiang, S. Social and Economic Impacts of Climate Change. Science (2016). 10.1126/science.aad9837.

[28] Global Update - Glasgow's 2030 credibility gap. Tech. Rep. November, Climate Action Tracker (2021). URL https://climateactiontracker.org/documents/997/ CAT_2021-11-09_Briefing_Global-Update_Glasgow2030CredibilityGap.pdf.

[29] Hallegatte, S., Hourcade, J. C. \& Dumas, P. Why economic dynamics matter in assessing climate change damages: Illustration on extreme events. Ecological Economics 62, 330-340 (2007). 10.1016/j.ecolecon.2006.06.006. 
[30] Hallegatte, S. \& Dumas, P. Can natural disasters have positive consequences? Investigating the role of embodied technical change. Ecological Economics 68, 777-786 (2009). URL http://dx.doi.org/10.1016/j.ecolecon.2008.06.011. 10.1016/j.ecolecon.2008.06.011.

[31] R.A.A. Catastrophe Loss Development Study: 2013 Edition (Createspace Independent Pub, 2013). URL https://books.google.de/books?id=TalNnwEACAAJ.

[32] Hallegatte, S. et al. Overview: Building the resilience of the poor in the face of natural disasters. Tech. Rep., World Bank (2016). 10.1596/978-1-4648-1003-9_ov.

[33] Hallegatte, S. et al. Shock waves - Managing the Impacts of Climate Change on Poverty. Tech. Rep., The World Bank (2016). URL http: //www . journals . cambridge . org/abstract_S0022112081001535. 10.1017/S0022112081001535.

[34] Belasen, A. R. \& Polachek, S. W. How hurricanes affect wages and employment in local labor markets. American Economic Review 98, 49-53 (2008). 10.1257/aer.98.2.49.

[35] Xue, Z. \& Neumann, C. J. Frequency and motion of western North Pacific tropical cyclones. Tech. Rep., NOAA (1984). URL https://repository.library.noaa.gov/ view/noaa/7080.

[36] Blackwell, C. Power Law or Lognormal? Distribution of Normalized Hurricane Damages in the United States, 1900-2005. Natural Hazards Review 16, 04014024 (2015). URL http://ascelibrary.org/doi/10.1061/\%28ASCE\%29NH.1527-6996. 0000162. 10.1061/(ASCE)NH.1527-6996.0000162.

[37] Conte, M. N. \& Kelly, D. L. An imperfect storm: Fat-tailed tropical cyclone damages, insurance, and climate policy. Journal of Environmental Economics and Management 92, 677-706 (2018). URL https://doi.org/10.1016/j.jeem.2017.08.010. 10.1016/j.jeem.2017.08.010.

[38] Pielke, R. Economic 'normalisation' of disaster losses 1998-2020: a literature review and assessment. Environmental Hazards 20, 93-111 (2021). URL https://doi. org/10.1080/17477891.2020.1800440. 10.1080/17477891.2020.1800440. 
[39] Botzen, W. J., Estrada, F. \& Tol, R. S. Methodological issues in natural disaster loss normalisation studies. Environmental Hazards 20, 112-115 (2021). URL https: //doi.org/10.1080/17477891.2020.1830744. 10.1080/17477891.2020.1830744.

[40] Grinsted, A., Ditlevsen, P. \& Christensen, J. H. Normalized US hurricane damage estimates using area of total destruction, 19002018. Proceedings of the National Academy of Sciences of the United States of America 116, 23942-23946 (2019). 10.1073/pnas.1912277116.

[41] Geiger, T., Frieler, K. \& Levermann, A. High-income does not protect against hurricane losses'. Environmental Research Letters 11, 084012 (2016). 10.1088/17489326/aa88d8.

[42] Bakkensen, L. A. \& Mendelsohn, R. O. Risk and Adaptation: Evidence from Global Hurricane Damages and Fatalities. Journal of the Association of Environmental and Resource Economists $\quad 3 ， 555-$ 587 (2016). URL http://www.journals.uchicago.edu/doi/10.1086/685908. $10.1086 / 685908$.

[43] Muis, S., Verlaan, M., Winsemius, H. C., Aerts, J. C. \& Ward, P. J. A global reanalysis of storm surges and extreme sea levels. Nature Communications 7, 12 (2016). 10.1038/ncomms11969.

[44] Li, M., Zhang, F., Barnes, S. \& Wang, X. Assessing storm surge impacts on coastal inundation due to climate change: case studies of Baltimore and Dorchester County in Maryland. Natural Hazards 103, 2561-2588 (2020). 10.1007/s11069-020-04096-4.

[45] Marto, R., Papageorgiou, C. \& Klyuev, V. Building Resilience to Natural Disasters: An Application to Small Developing States 28 (2017). URL http://0-search. ebscohost . com. wam. city . ac . uk/login . aspx?direct=true\&db=eoh\&AN=1679041\&site=ehostlive\%0Ahttp: //www. imf . org/external/pubs/cat/longres. aspx?sk=45329\% OAhttp: //www.imf .org/external/pubs/cat/longres. aspx?sk=45329.

[46] Bakkensen, L. A., Park, D. S. R. \& Sarkar, R. S. R. Climate costs of tropical cyclone losses also depend on rain. Environmental Research Letters 13, 074034 (2018). 10.1088/1748-9326/aad056. 
[47] Khanam, M. et al. Impact of compound flood event on coastal critical infrastructures considering current and future climate. Natural Hazards and Earth System Sciences 21, 587-605 (2021). 10.5194/nhess-21-587-2021.

[48] Hallegatte, S. An adaptive regional input-output model and its application to the assessment of the economic cost of Katrina. Risk Analysis 28, 779-799 (2008). 10.1111/j.1539-6924.2008.01046.x.

[49] Otto, C., Willner, S. N., Wenz, L., Frieler, K. \& Levermann, A. Modeling losspropagation in the global supply network: The dynamic agent-based model acclimate. Journal of Economic Dynamics and Control 83, 232-269 (2017). URL https://doi.org/10.1016/j.jedc.2017.08.001. 10.1016/j.jedc.2017.08.001.

[50] Willner, S. N., Otto, C. \& Levermann, A. Global economic response to river floods. Nature Climate Change 8, 594-598 (2018). 10.1038/s41558-018-0173-2.

[51] Kousky, C. \& Cooke, R. M. Climate Change and Risk Management (2009). URL http://citeseerx.ist.psu.edu/viewdoc/download?doi=10.1.1.860. $6241 \& r e p=r e p 1 \&$ type $=$ pdf.

[52] Kates, R. W., Colten, C. E., Laska, S. \& Leaterman, S. P. Reconstruction of New Orleas after Hurricane Katrina: A research perspective. Proceedings of the National Academy of Sciences 103, 14563 (2006). 10.1073/pnas.0605726103.

[53] Herring, S. C., Hoerling, M. P., Peterson, T. C. \& Stott, P. A. Explaining extreme events of 2019 from a climate perspective. Bulletin of the American Meteorological Society 102, 115 (2019). 10.1175/1520-0477-95.9.s1.1.

[54] Hallegatte, S., Vogt-Schilb, A., Bangalore, M. \& Rozenberg, J. Unbreakable - Building the Resilience of the Poor in the Face of Natural Disasters. Tech. Rep., World Bank (2016).

[55] Hallegatte, S., Rentschler, J. \& Walsh, B. Building Back Better - Achieving resilience through stronger , faster, and more inclusive post-disaster reconstruction (2018). URL http://documents . worldbank. org/curated/en/420321528985115831/Building- 
back-better-achieving-resilience-through-stronger-faster-and-moreinclusive-post-disaster-reconstruction.

[56] Climate-resilient Infrastructure. (2018). URL https://www. oecd.org/environment/ $\mathrm{cc} /$ policy-perspectives-climate-resilient-infrastructure.pdf.

[57] Siders, A. R., Hino, M. \& Mach, K. J. The case for strategic and managed climate retreat. Science Policy Forum 365, 6455 (2019). 10.1126/science.

[58] Carey, J. \& Writer, S. Managed retreat increasingly seen as necessary in response to climate change's fury. Proceedings of the National Academy of Sciences of the United States of America 117, 13182-13185 (2020). 10.1073/pnas.2008198117.

[59] Martinez-Diaz, L., Sidner, L. \& McClamrock, J. The Future of Disaster Risk Pooling for Developing Countries: Where Do We Go from Here? (2019). URL http://www. wri.org/publication/disaster-risk-pooling.

[60] Barro, R. J. \& Sala-i Martin, X. Economic Growth (MIT Press, Cambridge, MA, 1999), second edn.

[61] Cohen, A. J. Prices, capital, and the one-commodity model in neoclassical and classical theories. History of Political Economy 21, 231-251 (1989). 10.1215/0018270221-2-231.

[62] Hallegatte, S. Economic Resilience - Definition and Measurement. Policy Research Working Paper 6852, 1-46 (2014).

[63] Geiger, T., Frieler, K. \& Bresch, D. N. A global historical data set of tropical cyclone exposure (TCE-DAT). Earth System Science Data 10 (2018). 10.5194/essd-10-1852018.

[64] Grinsted, A., Moore, J. C. \& Jevrejeva, S. Homogeneous record of Atlantic hurricane surge threat since 1923. Proceedings of the National Academy of Sciences 109, 19601-19605 (2012). 10.1073/pnas.1209542109.

[65] Pachauri, R. K. \& Meyer, L. (eds.) IPCC, 2014: Climate Change 2014: Synthesis Report. (IPCC, Geneva, 2014). URL https://www.ipcc.ch/report/ar5/syr/. 
[66] Knapp, K. R., Kruk, M. C., Levinson, D. H., Diamond, H. J. \& Neumann, C. J. The International Best Track Archive for Climate Stewardship (IBTrACS). Bulletin of the American Meteorological Society 91, 363-376 (2010). 10.1175/2009BAMS2755.1. 


\section{B Supplementary information}

\section{B.1 Supplementary tables and figures for the US}

Tbl. S1. Historical hurricanes that made landfall in the US between 1980 and 2014. $1^{\text {st }}$ through $4^{\text {th }}$ columns list names and years of landfall of the storms as reported by the IBTRaCS database ${ }^{66}$, storm severity (category 4-5 hurricanes according to Saffir-Simpsons scale ${ }^{8}$ ), and storm surge index according to ref. ${ }^{64}$, respectively. The $5^{\text {th }}$ column reports categorized asset losses based on reported asset losses by Munich Re's NatCatSERVICE database ${ }^{1}$ : small $\left(>10^{-4} \%\right)$, moderate $\left(>10^{-3} \%\right)$, strong $\left(>10^{-2} \%\right)$, severe $\left(>10^{-1} \%\right)$. The asset losses are measured relative to the growth domestic product of the US (according to World Banks' and OECD's National Accounts database ${ }^{5}$ ) in the year of landfall.

\begin{tabular}{rccrc}
\hline Name & Year & $\begin{array}{c}\text { Cat. 4-5 } \\
\text { hurricane }\end{array}$ & $\begin{array}{r}\text { Surge } \\
\text { index }\end{array}$ & $\begin{array}{c}\text { Asset losses } \\
\text { category }\end{array}$ \\
\hline Alberto & 1994 & & 9.2 & strong \\
Alicia & 1983 & & 52.7 & strong \\
Allen & 1980 & $\mathrm{x}$ & 36.4 & strong \\
Allison & 1989 & & 20.8 & moderate \\
Allison & 2001 & & 24.1 & strong \\
Andrew & 1992 & $\mathrm{x}$ & 23.4 & severe \\
Arlene & 1993 & & 11.5 & small \\
Barry & 2001 & & 9.8 & small \\
Bertha & 1996 & & 16.4 & moderate \\
Beryl & 1994 & & 4.6 & moderate \\
Bill & 2003 & & 9.4 & small \\
Bob & 1985 & & 6.8 & small \\
Bob & 1991 & & 3.4 & strong \\
Bonnie & 1986 & & 14.6 & small \\
Bonnie & 1998 & & 22.7 & strong \\
Bonnie & 2004 & & 5.8 & small \\
Bret & 1999 & $x$ & 4.7 & moderate \\
Chantal & 1989 & & 11.9 & moderate \\
Charley & 2004 & $x$ & 3.2 & severe \\
Charley & 1986 & & 7.8 & small \\
Charley & 1998 & & 12.7 & moderate \\
Cindy & 2005 & & 1.9 & moderate \\
Claudette & 2003 & & 55.1 & moderate
\end{tabular}




\begin{tabular}{|c|c|c|c|c|}
\hline Name & Year & $\begin{array}{l}\text { Cat. 4-5 } \\
\text { hurricane }\end{array}$ & $\begin{array}{l}\text { Surge } \\
\text { index }\end{array}$ & $\begin{array}{c}\text { Asset losses } \\
\text { category }\end{array}$ \\
\hline Danielle & 1980 & & 2.6 & small \\
\hline Danny & 1985 & & 14.5 & moderate \\
\hline Danny & 1997 & & 19.1 & moderate \\
\hline Debby & 2012 & & 8.1 & moderate \\
\hline Dennis & 2005 & $x$ & 108.1 & strong \\
\hline Dennis & 1981 & & 5.6 & small \\
\hline Dennis & 1999 & & 5.3 & moderate \\
\hline Diana & 1984 & $x$ & 9.6 & moderate \\
\hline Dolly & 2008 & & 7.9 & moderate \\
\hline Earl & 1998 & & 22.7 & small \\
\hline Edouard & 1996 & $x$ & 2.6 & small \\
\hline Elena & 1985 & & 33 & strong \\
\hline Emily & 1993 & & 7.3 & small \\
\hline Erin & 1995 & & 30.3 & moderate \\
\hline Erin & 2007 & & 7.9 & small \\
\hline Ernesto & 2006 & & 7.2 & moderate \\
\hline Fay & 2008 & & 6.9 & moderate \\
\hline Florence & 1988 & & 9.2 & small \\
\hline Floyd & 1999 & $x$ & 17.6 & strong \\
\hline Fran & 1996 & & 4.4 & strong \\
\hline Frances & 2004 & $x$ & 9.4 & strong \\
\hline Frances & 1998 & & 25.8 & moderate \\
\hline Gabrielle & 2001 & & 5.4 & moderate \\
\hline Gaston & 2004 & & 5 & small \\
\hline Georges & 1998 & $x$ & 85.4 & strong \\
\hline Gilbert & 1988 & $x$ & 9.5 & moderate \\
\hline Gloria & 1985 & & 15.7 & strong \\
\hline Gordon & 1994 & & 6.1 & moderate \\
\hline Gordon & 2000 & & 7 & small \\
\hline Gustav & 2008 & $x$ & 71 & strong \\
\hline Hanna & 2008 & & 2.3 & small \\
\hline Hermine & 2010 & & 8.5 & moderate \\
\hline Hugo & 1989 & $x$ & 25.9 & severe \\
\hline Humberto & 2007 & & 7.9 & small \\
\hline
\end{tabular}




\begin{tabular}{|c|c|c|c|c|}
\hline Name & Year & $\begin{array}{l}\text { Cat. 4-5 } \\
\text { hurricane }\end{array}$ & $\begin{array}{l}\text { Surge } \\
\text { index }\end{array}$ & $\begin{array}{c}\text { Asset losses } \\
\text { category }\end{array}$ \\
\hline Ida & 2009 & & 16.3 & moderate \\
\hline Ike & 2008 & $x$ & 105.1 & severe \\
\hline Iniki & 1992 & & 3.9 & strong \\
\hline Irene & 1999 & & 10.8 & moderate \\
\hline Irene & 2011 & & 55.6 & strong \\
\hline Isaac & 2012 & & 80.3 & strong \\
\hline Isabel & 2003 & $x$ & 8.1 & strong \\
\hline Iselle & 2014 & & 3.5 & small \\
\hline Isidore & 1984 & & 5.5 & small \\
\hline Isidore & 2002 & & 47.4 & moderate \\
\hline Ivan & 2004 & $x$ & 53 & severe \\
\hline Iwa & 1982 & & 2.5 & moderate \\
\hline Jeanne & 2004 & & 14 & strong \\
\hline Jerry & 1989 & & 6.8 & small \\
\hline Josephine & 1996 & & 10.1 & moderate \\
\hline Juan & 1985 & & 34.1 & strong \\
\hline Kate & 1985 & & 8.4 & moderate \\
\hline Katrina & 2005 & $x$ & 114.4 & severe \\
\hline Keith & 1988 & & 9.4 & small \\
\hline Lee & 2011 & & 14.9 & strong \\
\hline Lili & 2002 & $x$ & 5.6 & strong \\
\hline Marco & 1990 & & 6.7 & small \\
\hline Mitch & 1998 & $x$ & 5.1 & moderate \\
\hline Opal & 1995 & $x$ & 59.3 & strong \\
\hline Ophelia & 2005 & & 6.1 & small \\
\hline Paul & 2006 & & 13.7 & small \\
\hline Rita & 2005 & $x$ & 35.6 & severe \\
\hline Sandy & 2012 & & 15.7 & severe \\
\hline Tammy & 2005 & & 5.6 & small \\
\hline Wilma & 2005 & $x$ & 55.1 & severe \\
\hline$?$ & 1987 & & - & small \\
\hline
\end{tabular}




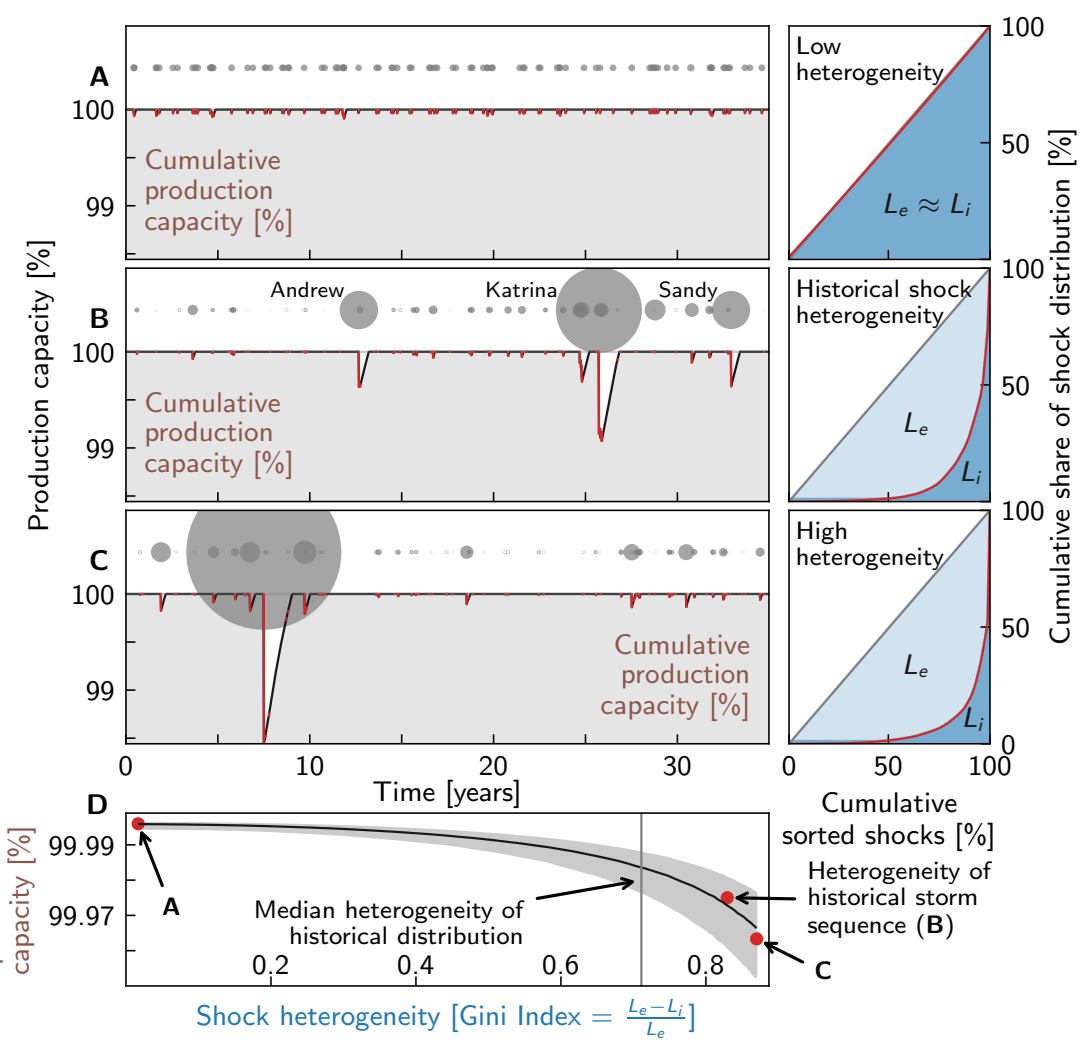

Fig. S1. Recovery dynamics of production capacity in dependence of shock heterogeneity for $1 \%$ reconstruction investment limit. Same as Fig. 2 but for a $1 \%$ reconstruction investment cap.

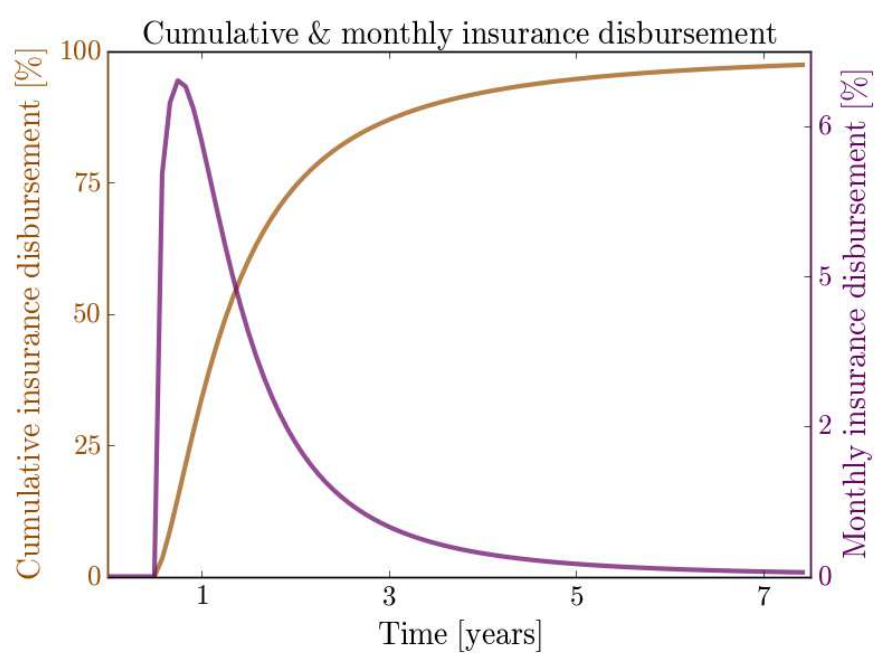

Fig. S2. Insurance payout dynamics. Cumulative (brown) and monthly (violet) insurance payouts in the aftermath of an individual shock to the physical capital stock. The sigmoidal function for the cumulative payouts is calibrated such that $60 \%(90 \%)$ of the insured values are reimbursed within one (three) year(s) according to insurance data of the Reinsurance Association of America $^{31}$. The monthly payouts are then obtained by deriving this function with respect to time. 

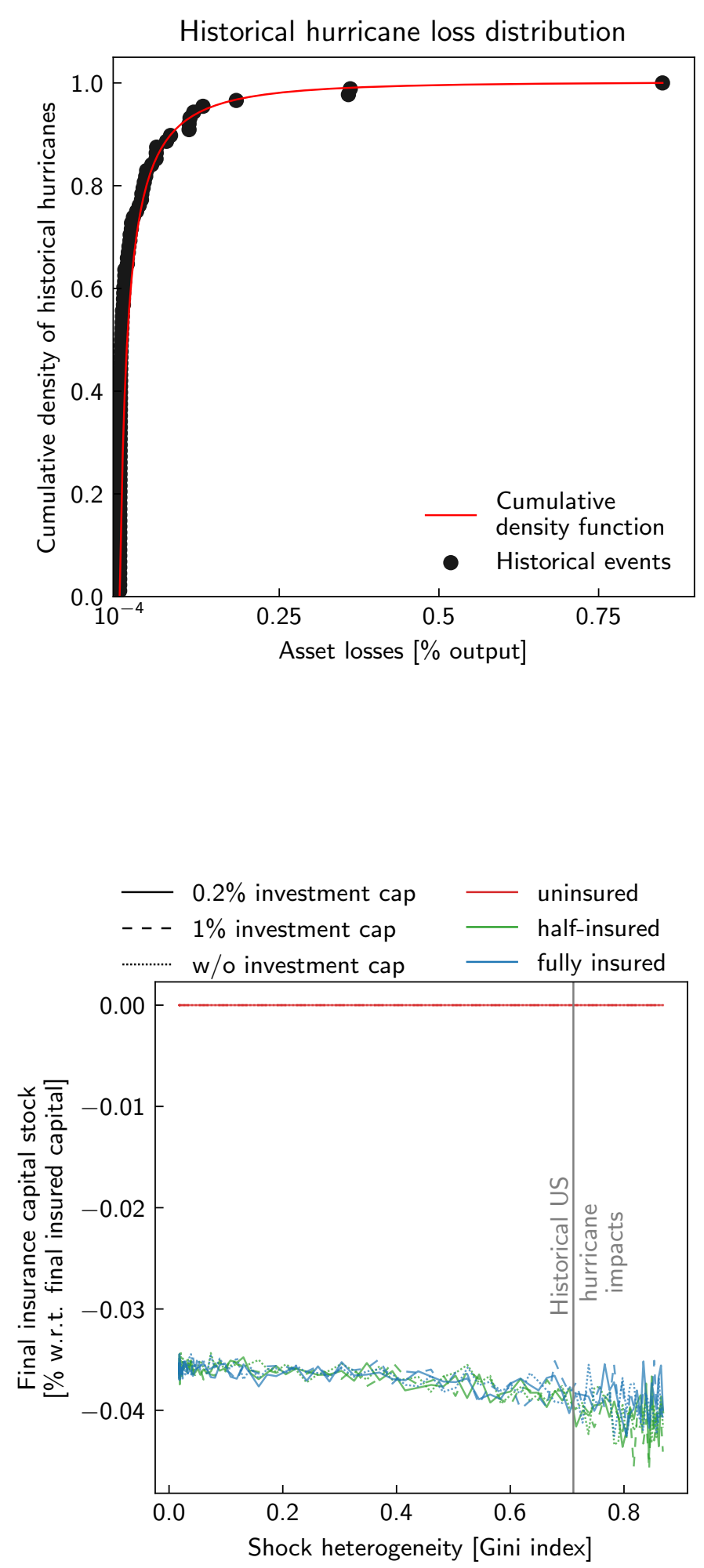

Fig. S3. Distribution of the historical asset losses of hurricanes that made landfall in the US in the period 1980-2014.

Black dots depict the asset losses as reported by the NatCatSERVICE database ${ }^{1}$ in the period 1980-2014 relative to the US growth domestic product of the years in which the hurricanes made landfall. The red line depicts a fit with a log-normal cumulative density function.
Fig. S4. Insurance is non-profit. Median insurance capital stock in terms of the insured potential capital stock after $\mathcal{T}=35$ years. Same scenarios and colour code as in Fig. 1. 


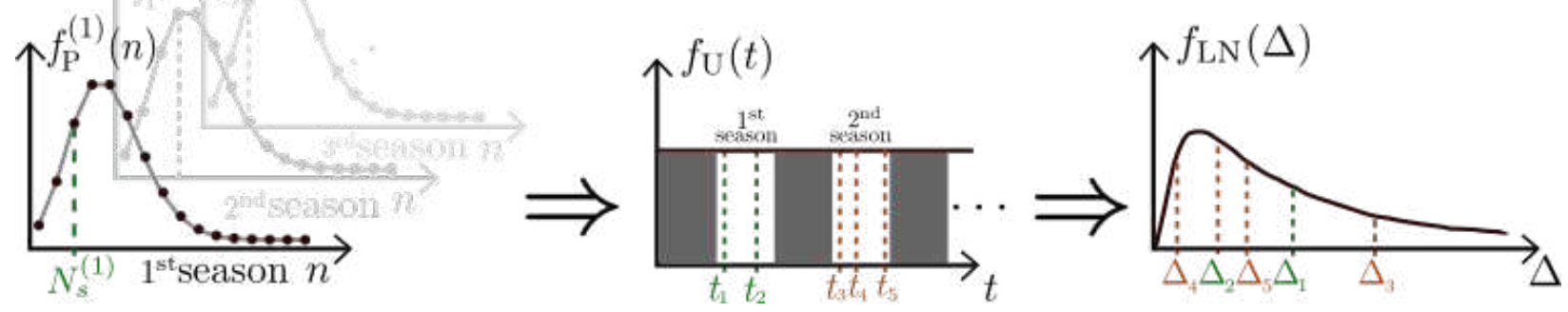

Fig. S5. Sketch of construction of synthetic asset loss time series caused by hurricanes with landfall. Synthetic time series of asset losses are generated in three steps: First, the number of hurricane shocks in each US hurricane season (June-November) is drawn from a Poisson distribution $f_{p}$. Second, the times of landfalls are determines assuming the same probability of landfall within each season, excluding the possibility of two landfalls on the same day. Third, the relative asset loss of each landfall is drawn from the log-normal distribution of Fig. S3.

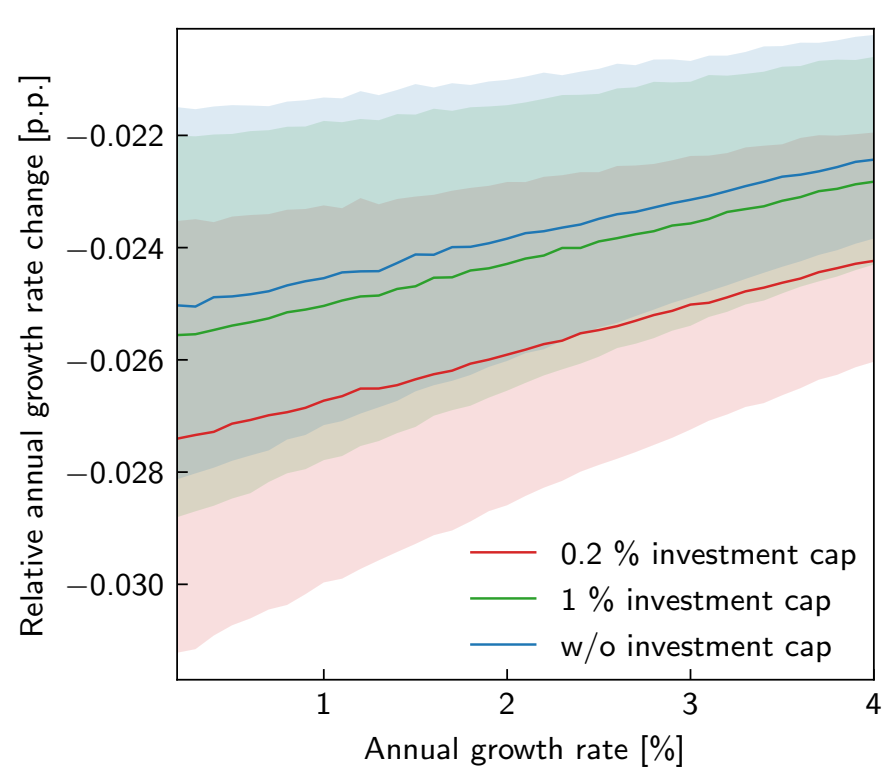

Fig. S6. Robustness of relative growth losses with regard to choice of baseline growth rate. Dependence of relative annual growth losses upon the growth rate of corresponding unperturbed baseline scenario for an insurance coverage of $50 \%$ without reconstruction investment limit (blue) as well as for for reconstruction investment caps of $0.2 \%$ (red) and $1 \%$ (green) of weekly output. Lines indicate median growth rate reductions and shaded areas the corresponding 16.7-88.3 percentile confidence intervals. 


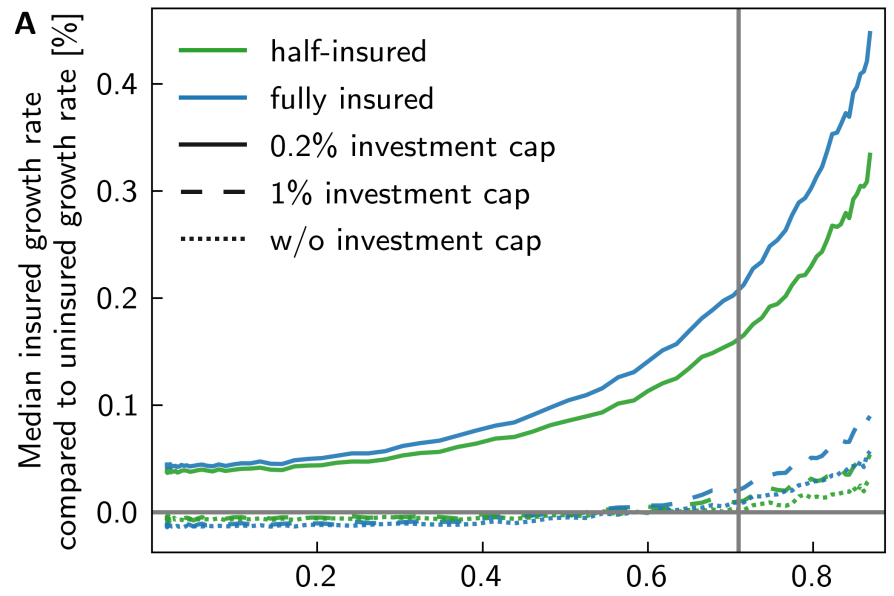

Shock heterogeneity [Gini index]

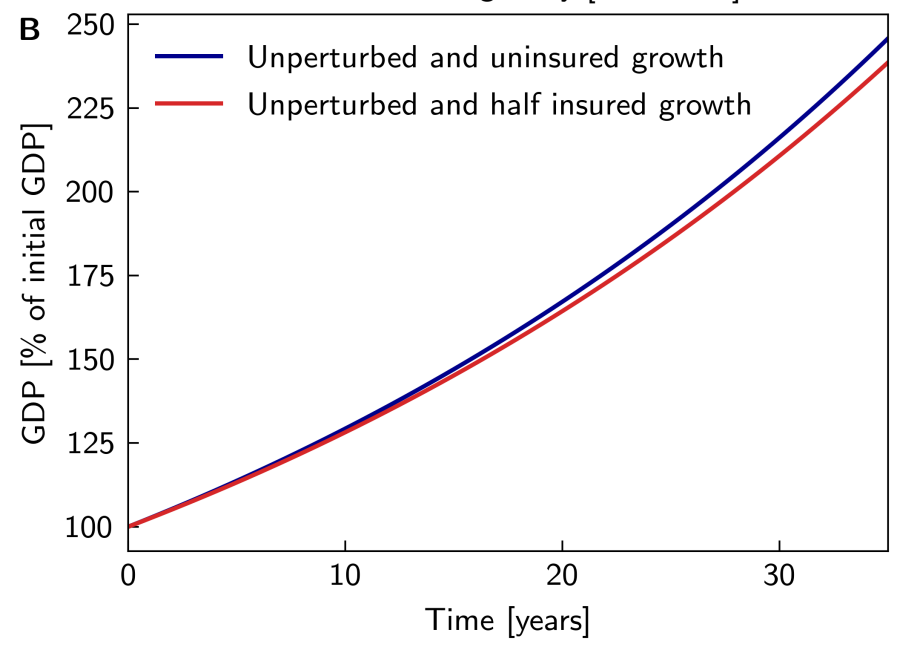

Fig. S7. Impact of insurance coverage on economic growth.

A: Change of median growth rate for half (green lines) and fully (blue lines) insured economies with regard to an economy without insurance in dependence of shock heterogeneity for reconstruction investments capped to $0.2 \%$ (solid), $1 \%$ (dashed) of weekly output and without investment cap (dotted). The vertical gray solid line denotes the median Gini index of the historical shock distribution. Parameters as in Tbl. 1.

B: GDP time series for an unperturbed and uninsured economy (blue solid line) and an unperturbed but half insured economy (red solid line) for the historical period of 35 years. Parameters as in Tbl. 1. 

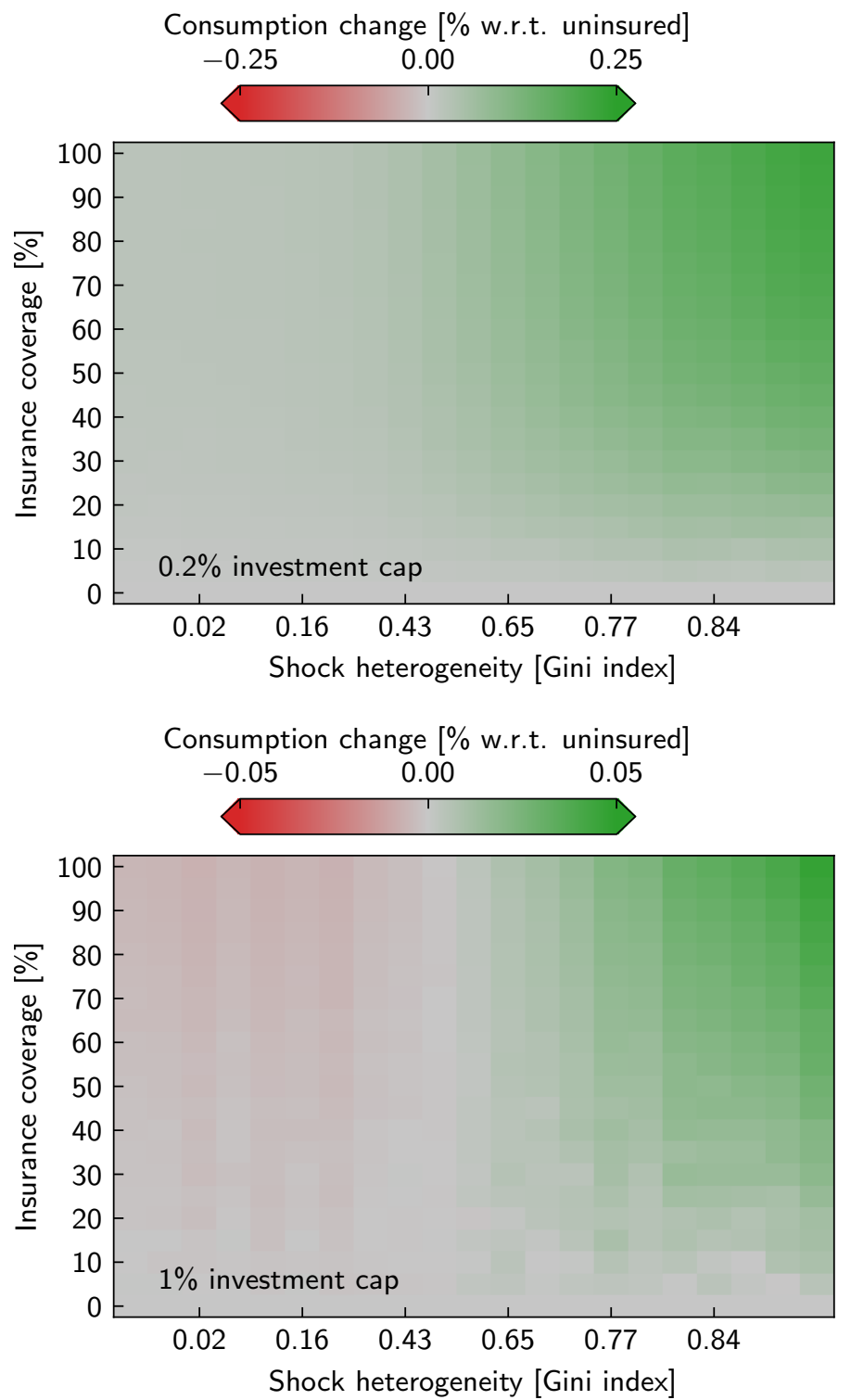

Consumption change [\% w.r.t. uninsured] $\begin{array}{lll}-0.05 & 0.00 & 0.05\end{array}$

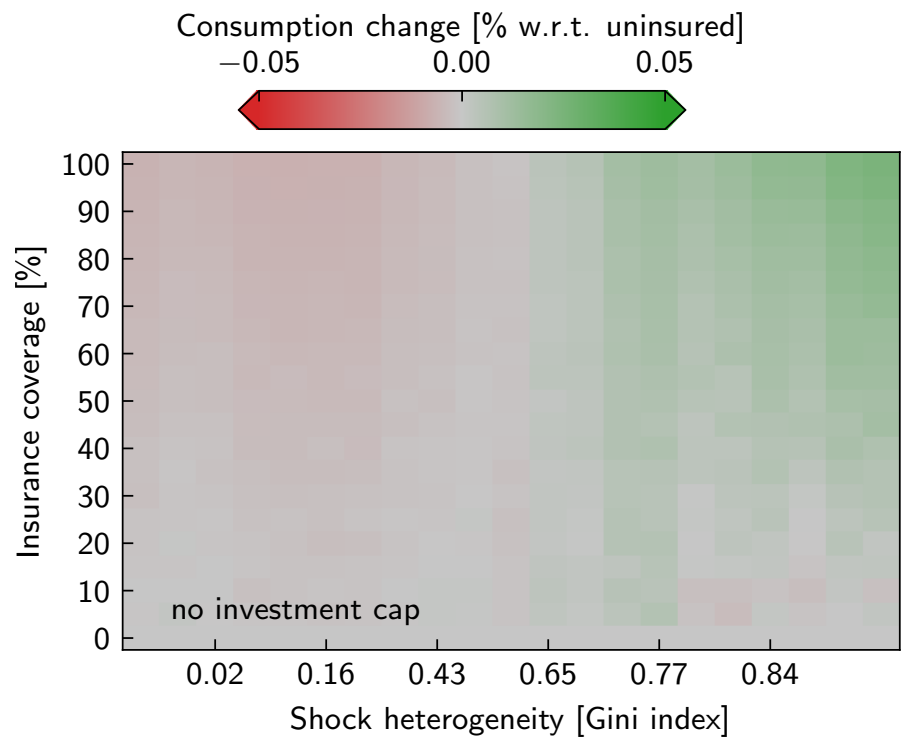

Fig. S8. Consumption change in dependence of shock heterogeneity and insurance coverage. Parameters as in Tbl. 1. 


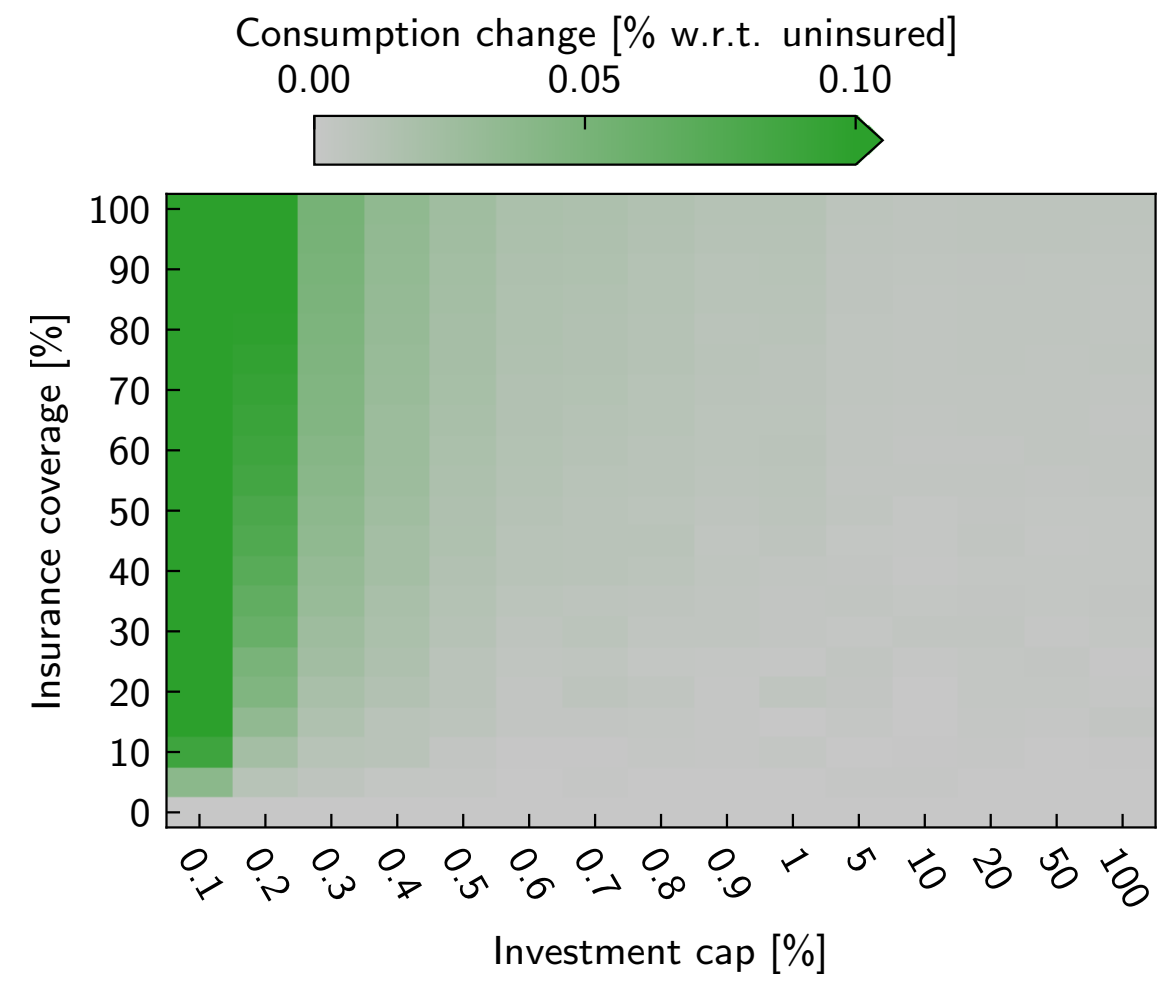

Fig. S9. Consumption change in dependence of insurance coverage and investment cap. Parameters as in Tbl. 1. 


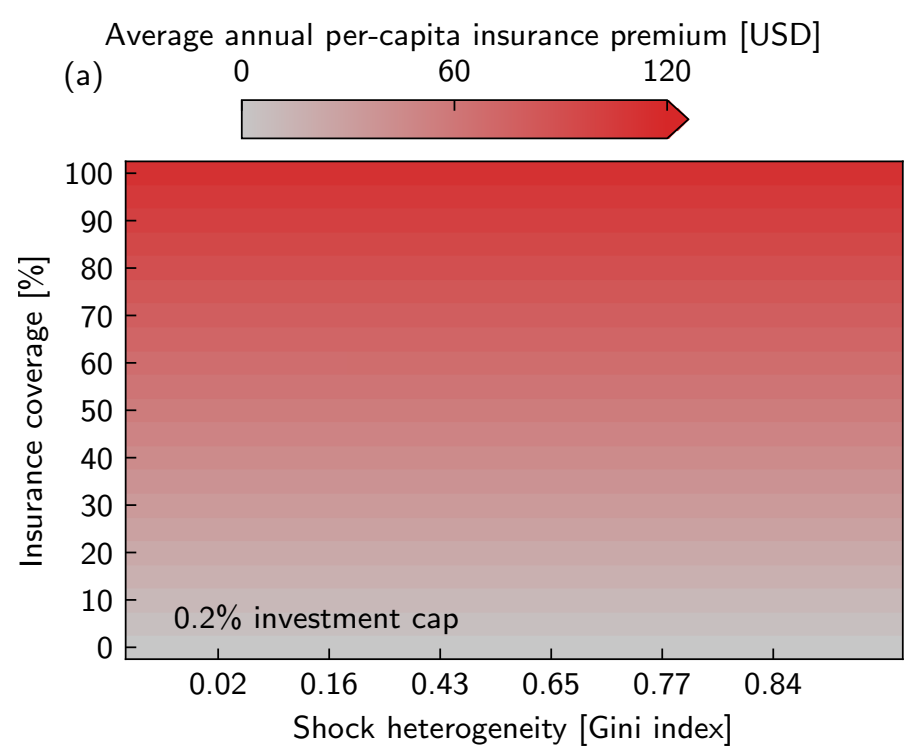

Insurance premium relative to consumption [\%]
(b)
0.0000
0.0025
0.0050

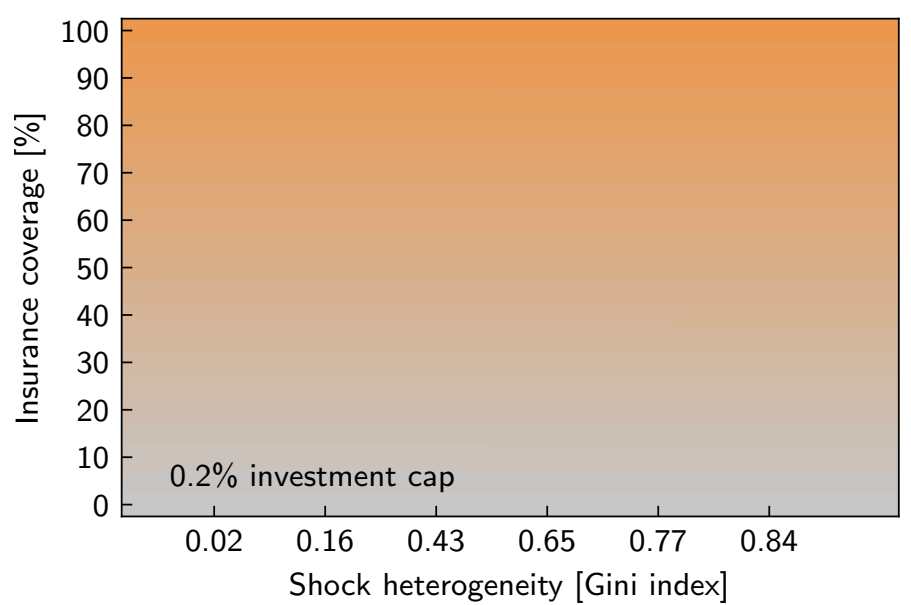

Fig. S10. Average annual insurance premium in dependence of shock heterogeneity and insurance coverage.

A: Absolute per-capita insurance premium in US\$. B: Insurance premium relative to average consumption. Parameters: investment cap: $0.2 \%$ of weekly output; other parameters as in Tbl. 1. 


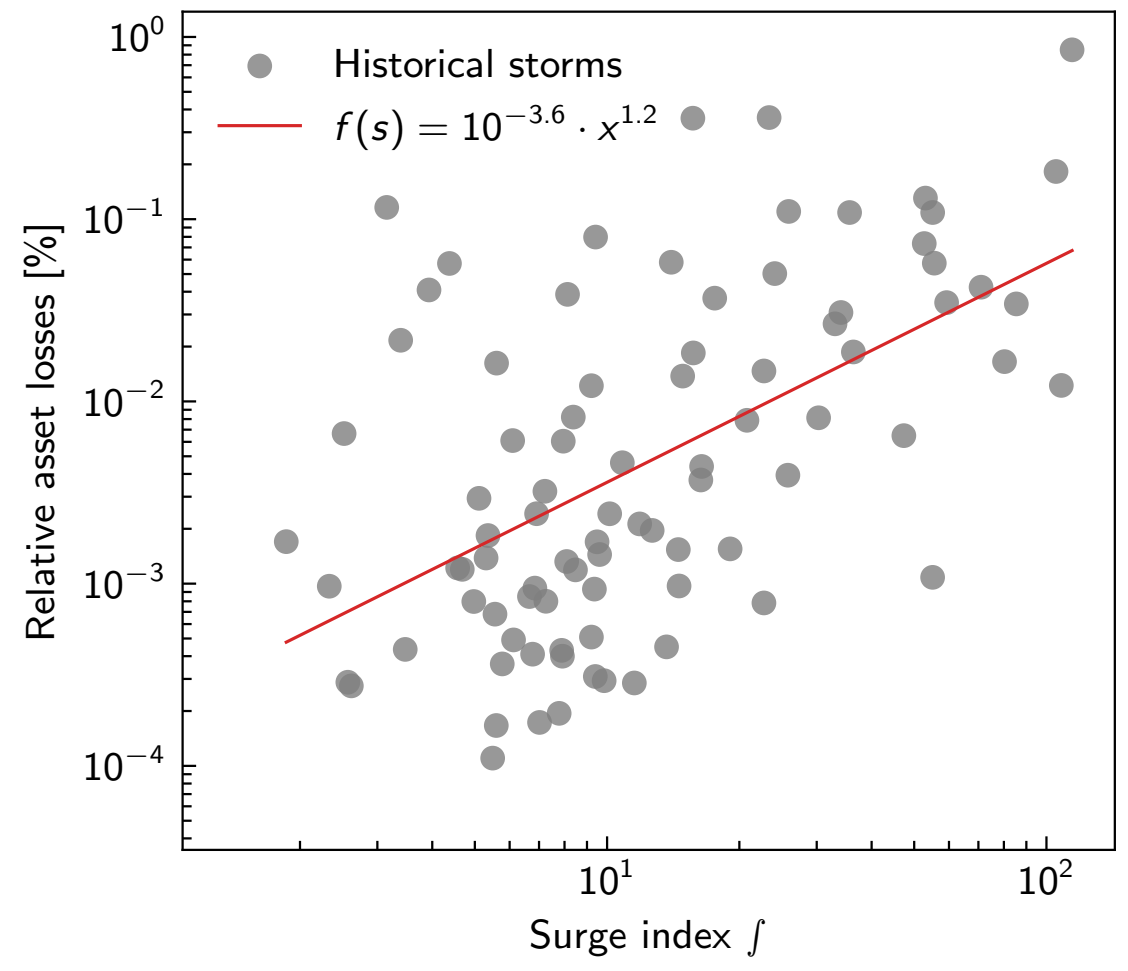

Fig. S11. Dependence of asset losses on surge index. Log-log plot of asset losses (grey dots) of the 88 historical hurricane that made landfall in the US between 1980 and 2014 according to NatCatSERVICE database ${ }^{1}$ relative to the growth domestic output the year of landfall (according to the World Banks' and OECD's National Accounts database ${ }^{a}$ ) as function of their surge index ${ }^{64}$. The red line denotes a non-linear fit of the data (damage function $f(f)$ ). The Pearson's chi-squared criteria for the goodness-of-fit is $\chi^{2}=0.59$ ).

${ }^{a}$ https://data.worldbank.org/indicator/NY.GDP.PCAP.CD 


\section{B.2 The case of the Small Island Developing State of Haiti}

In this section, we repeat the modeling exercise described in the main text to the tropical cyclone prone Small Island Developing State of Haiti. According to MunichRe's NatCatSERVICE ${ }^{1}$ database, Haiti experienced 18 tropical cyclones with landfalls in the study period 1980-2014 (Tbl. S3). The direct asset losses (relative to the growth domestic product of the years the hurricanes made landfall) accumulate to $11.86 \%$. After fitting them with a log-normal distribution, we obtain a median Gini index of 0.58 . Driving the model with the parameters of Tbls. 1 and S2, we find that, as for the US, growth losses increase non-linearly with shock heterogeneity but decrease with insurance coverage (cf. Fig. 3 with Fig. S12. Noteworthy, according to NatCatSERVICE none of the tropical cyclone damages were insured in the historical study period, compared to $50 \%$ in the US. Further, we assume the same insurance payout dynamics as for the US since there are no data available for Haiti.

\section{B.2.1 Future projections of damages}

Due to the lack of better data and to use the same method, we assume for the storm surge-based estimate that the scaling of the return frequencies of tropical cyclone induces storm surges with global warming is the same as in the US. Further, assuming that the number of events remains unchanged compared to the historical study period, we find an increase of cumulative relative asset losses of $13.89 \%$ and $17.60 \%$ for the $+2^{\circ} \mathrm{C}$ and $+2.7^{\circ} \mathrm{C}$ degree scenarios, respectively. Growth losses more than double and tripple for the $+2^{\circ} \mathrm{C}$ and $+2.7^{\circ} \mathrm{C}$ degree scenarios, respectively (appendix B.2.1). According to the wind-speed based estimate, the total number of events declines to 14 landfalls for both, the $+2^{\circ} \mathrm{C}$ and $+2.7^{\circ} \mathrm{C}$ degree scenarios which results in moderate decreases of cumulative relative asset losses to $11.82 \%$ and $11.76 \%$, respectively. In consequence, median growth losses also slightly decrease compared to the historical period (appendix B.2.1. As for the US, increasing insurance coverage allows mitigating the additional climate change induced growth losses arising for the storm surge-based estimate. However, it is important to note that already in the historical period Haiti suffered growth losses which may be unsustainably high. 


\begin{tabular}{lccr} 
Quantity & Symbol & Value & Unit \\
\hline Initial GDP per capita & $y^{0}$ & 1402.1 & US\$ \\
GDP growth rate & $g$ & $1.95 \%$ & year $^{-1}$ \\
\hline Cumulative relative historical asset losses & $\Delta_{\mathcal{T}}$ & 11.86 & $\%$ \\
Number of historical landfalling hurricanes & $N_{S}$ & 18 & \\
Standard deviation of historical & & & \\
log-normal asset loss distribution & $\sigma_{0}$ & 1.3909 & \\
\hline
\end{tabular}

Tbl. S2. Exogenous parameters used in the numerical simulations for Haiti that differ from the parameters used for the US in Tbl. 1

Tbl. S3. Historical tropical cyclones that made landfall in Haiti between 1980 and 2014. $1^{\text {st }}$ through $4^{\text {th }}$ columns list names and years of landfall of the storms as reported by the IBTRaCS database ${ }^{66}$, storm severity (category $4-5$ hurricanes according to SaffirSimpsons scale ${ }^{8}$ ), and storm surge index according to ref. ${ }^{64}$, respectively. The $5^{\text {th }}$ column reports categorized asset losses based on reported asset losses by Munich Re's NatCatSERVICE database ${ }^{1}:$ small $\left(>10^{-4} \%\right)$, moderate $\left(>10^{-3} \%\right)$, strong $\left(>10^{-2} \%\right)$, severe $\left(>10^{-1} \%\right)$, devastating $(>1 \%)$. The asset losses are measured relative to the growth domestic product of the US (according to World Banks' and OECD's National Accounts database $\left.^{6}\right)$ in the year of landfall.

\begin{tabular}{|c|c|c|c|c|}
\hline Name & Year & $\begin{array}{l}\text { Cat. 4-5 } \\
\text { hurricane }\end{array}$ & $\begin{array}{l}\text { Surge } \\
\text { index }\end{array}$ & $\begin{array}{c}\text { Asset losses } \\
\text { category }\end{array}$ \\
\hline Allen & 1980 & $x$ & 36.4 & devastating \\
\hline Alpha & 2005 & & - & moderate \\
\hline Dean & 2007 & $x$ & - & moderate \\
\hline Dennis & 2005 & $x$ & 108.1 & severe \\
\hline Ernesto & 2006 & & 7.2 & moderate \\
\hline Georges & 1998 & $x$ & 6.9 & devastating \\
\hline Gilbert & 1988 & $x$ & 85.4 & moderate \\
\hline Gordon & 1994 & & 9.5 & severe \\
\hline Gustav & 2008 & $x$ & 6.1 & moderate \\
\hline Hanna & 2008 & & 71.0 & moderate \\
\hline Ike & 2008 & & 2.3 & moderate \\
\hline Irene & 2011 & & 105.1 & moderate \\
\hline Isaac & 2012 & & 55.6 & strong \\
\hline Jeanne & 2004 & & 80.3 & severe \\
\hline Noel & 2007 & & 14.0 & strong \\
\hline
\end{tabular}




\begin{tabular}{rrrrc}
\hline Name & Year & $\begin{array}{c}\text { Cat. 4-5 } \\
\text { hurricane }\end{array}$ & $\begin{array}{c}\text { Surge } \\
\text { index }\end{array}$ & $\begin{array}{c}\text { Asset losses } \\
\text { category }\end{array}$ \\
\hline Olga & 2007 & - & moderate \\
Sandy & 2012 & 15.7 & devastating \\
Sandy & 2008 & - & small \\
\hline
\end{tabular}

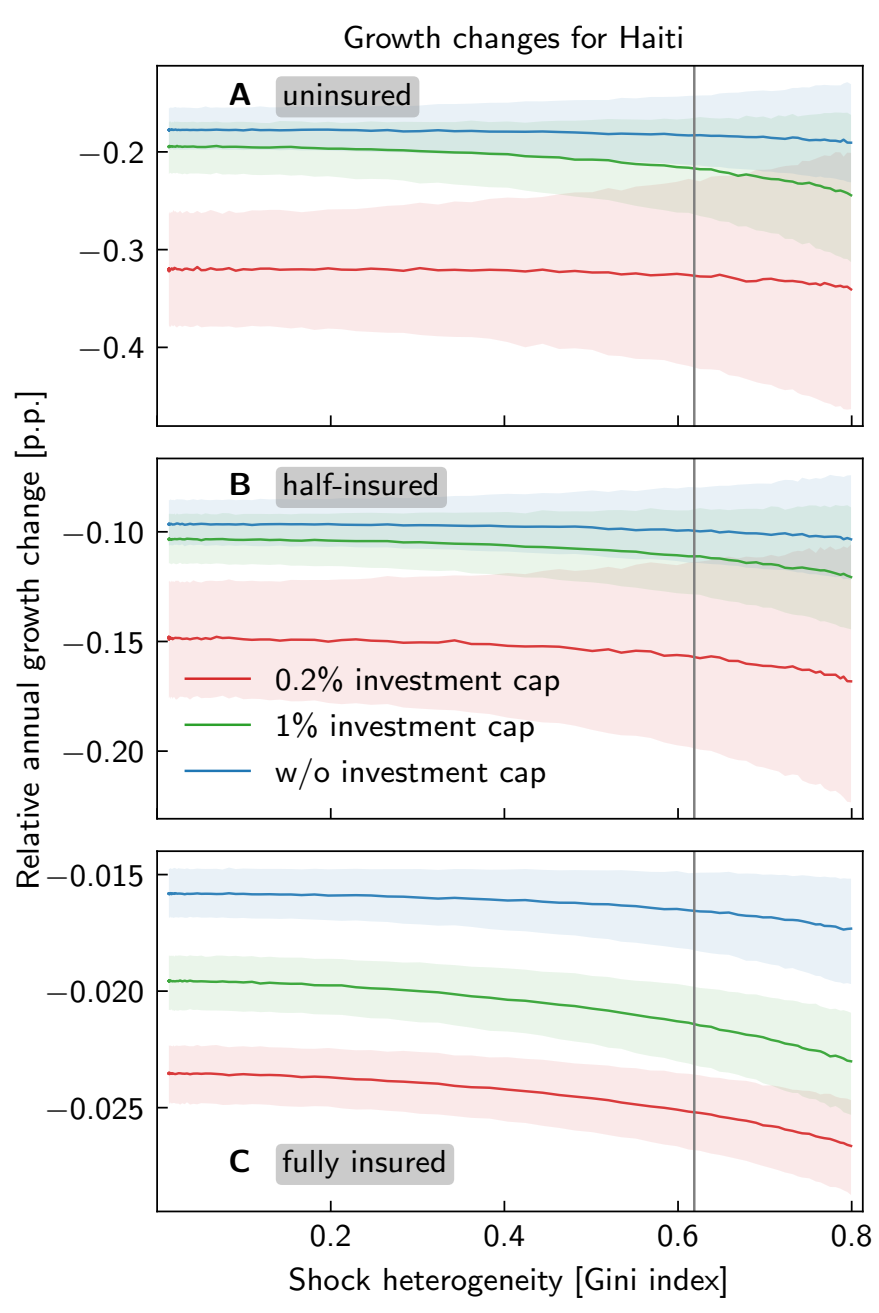

Fig. S12. Impact of hurricane shock heterogeneity on annual output growth rate of Haiti. Median annual growth rate change of the Haitian economy under hurricane shocks relative to the growth rate of the corresponding unperturbed economy, as a function of shock heterogeneity - measured by the Gini index - for no (A), half (B), and full (C) insurance coverage. Blue, green, and red lines depict median growth rate changes for scenarios where reconstruction investment is not limited, limited to $0.2 \%$, and $1 \%$ of weekly output, respectively; shaded areas mark the corresponding 16.7-83.3 percentile confidence intervals. The grey vertical line indicates the median Gini index of the historical distribution of relative direct asset losses. In each simulation run, the Haitian GDP per capita (1402.1 USD) grows initially with $1.95 \%$ per year and is threatened by 18 landfalling hurricane within 33 years, which add up to $11.86 \%$ capital damage. 


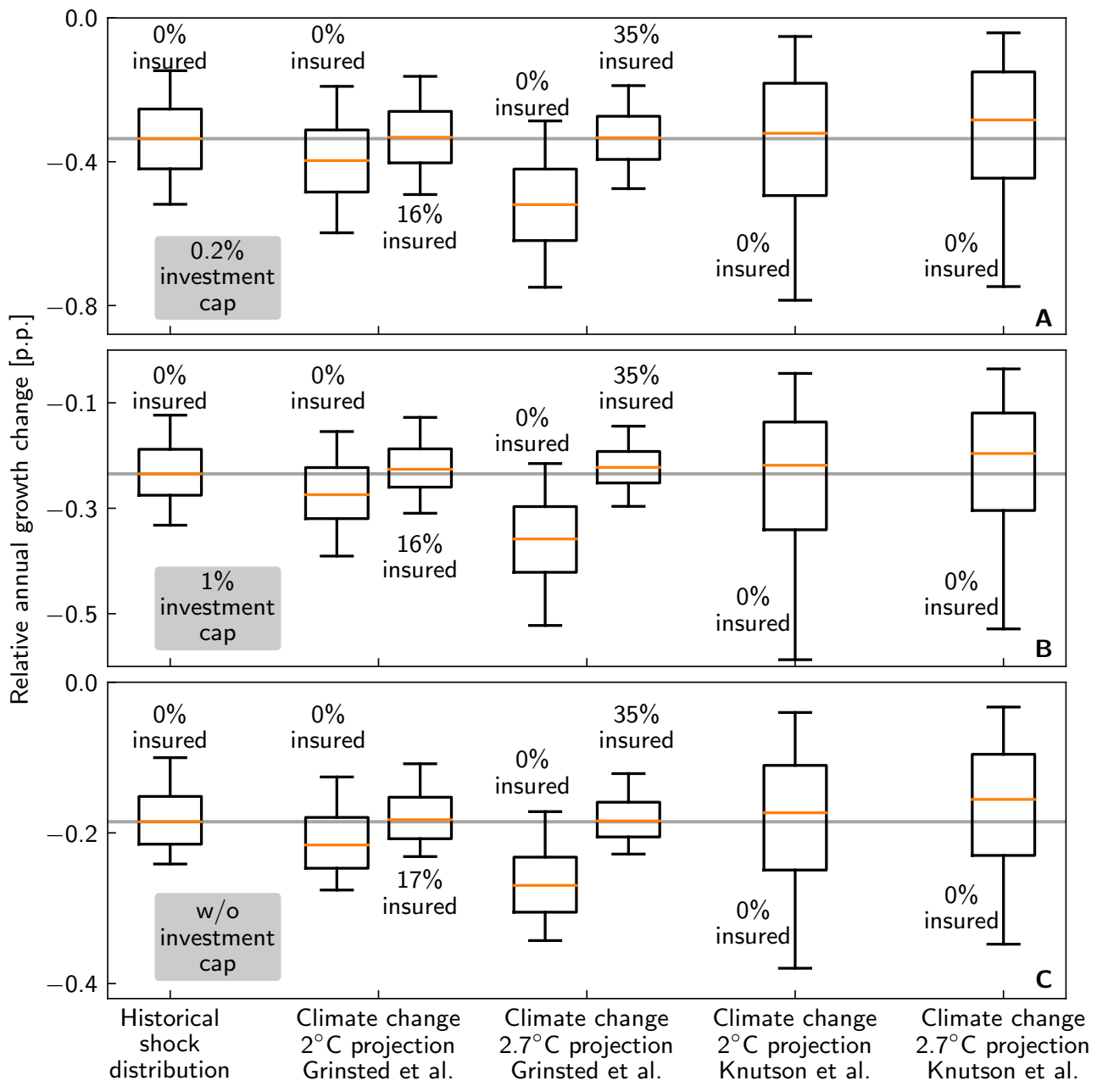

Fig. S13. Projected impacts of hurricanes on economic growth in $2^{\circ} \mathrm{C}$ and $2.7^{\circ} \mathrm{C}$ worlds and the effectiveness of insurance as coping strategy for Haiti. Annual growth losses (relative to the corresponding unperturbed economies evolving on the balanced growth paths) as obtained for the historical shock distribution ( $0 \%$ insurance coverage, period $1980-2012 ; 1^{\text {st }}$ column), for Paris-compatible $+2^{\circ} \mathrm{C}$ warming above pre-industrial levels $\left(2^{\text {nd }}, 3^{\text {rd }}, 6^{\text {th }}\right.$ and $7^{\text {th }}$ column) and $+2.7^{\circ} \mathrm{C}\left(4^{\text {th }}, 5^{\text {th }}, 8^{\text {th }}\right.$ and $9^{\text {th }}$ column $)$ warming in compliance with current policies for reconstruction investment caps of $0.2 \%$ (A, standard scenario), $1 \%$ (B) and without reconstruction investment cap (C). Climate change projections of growth losses are derived from two different methods to estimate climate change-induced changes in the return frequencies of hurricanes by Grinsted et al. ${ }^{6}$ and Knutson et al. ${ }^{7}$ ( $0 \%$ insurance coverage, $2^{\text {nd }}$ and $4^{\text {th }}$ column, respectively). Additionally, for both estimates and warming levels the insurance coverages that would be necessary to reduce growth losses to the historical level are shown $\left(3^{\text {rd }}, 5^{\text {th }}, 7^{\text {th }}\right.$ and $9^{\text {th }}$ column). Orange lines, boxes, and whiskers indicate median loss estimates as well as the $25^{\text {th }}-75^{\text {th }}$ and $5^{\text {th }}-95^{\text {th }}$ percentile ranges, respectively. 